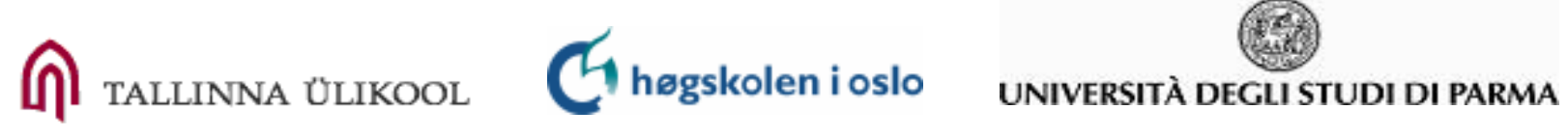
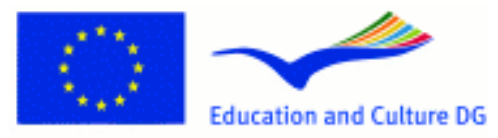

ERASMUS MUNDUS

Getaneh Agegn Alemu

\title{
The Role of Open Access in Fostering Knowledge Sharing and Collaboration in Ethiopia: a case study
}

\section{Supervisor: Sirje Virkus}




\section{Declaration}

I certify that all material in this dissertation which

is not my own work has been identified and that no material is

included for which a degree has previously been conferred upon me

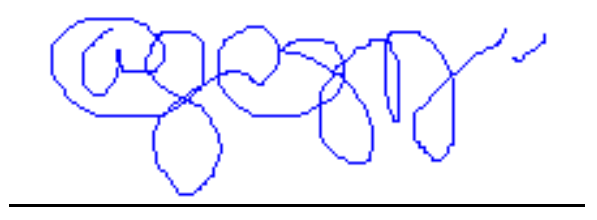

Getaneh Agegn Alemu 


\section{ACKNOWLEDGMENTS}

I am very much grateful to Sirje Virkus who has made my stay in Tallinn so academically fruitful. Her critical and insightful comments during her supervision have contributed greatly to this research. I also thank Raivo Ruusalepp for reviewing the thesis and for his critical comments which showed me the strengths and limitations of this research.

I owe many thanks to the following individuals who have read this thesis, offered critical comments and encouragement: Ato Getachew Bulfeto, Prof. Anna Maria Tammaro, Besim Kokollari, Prof. Sue Myburgh, Mulugeta Mengist, Mekdes Fisseha, Zelalem Mengistu and Kenaw Gebresellassie. I would also like to thank the librarians and researchers of AAU, MoST, EDRI, and ILRI for their cooperation with the interviews.

I thank my wife, Bethelhem Getachew, who has been extraordinarily patient of my absence and provided me with her unreserved love and care. I owe her a lot and may God help me repay all these.

I would like to acknowledge my Lecturers at Oslo University College, Parma University and Tallinn University. Last but not least, I thank my fellow students of DILL-2007 for being very nice friends. 


\begin{abstract}
This study adopts a qualitative approach and uses the case study method. Fourteen researchers and librarians were interviewed in four organizations in Addis Ababa, Ethiopia. The responses based on the semi-structured interviews provide information about the current status of scholarly communication, the awareness of researchers and librarians about open access and the actual and potential challenges in implementing open access strategies in Ethiopia. This research is believed to illuminate the practicalities and procedures of how open access scholarly communication models could foster and support knowledge sharing and collaboration among Ethiopian researchers.
\end{abstract}

The results of the study show that Ethiopian researchers suffer from lack of adequate access to scholarly literature. There is also lack of scholarly communication outlets to publish and disseminate their research results. This study reveals that the current scholarly communication system in Ethiopia is faced with technological and social challenges. Open access is proposed as a viable alternative for Ethiopia. The research indicates that if Ethiopian universities and research institutions adopt open access policies and strategies, it would help them improve the access and dissemination of scientific research results. A concerted effort is required from administrators, librarians, researchers, funding agencies and government to implement and fully harness open access in Ethiopia.

Keywords: open access, scholarly communication, institutional repositories, ETD, selfarchiving, open access journals, developing countries, Ethiopia 


\section{TABLE OF CONTENTS}

CHAPTER ONE

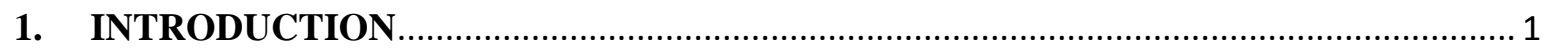

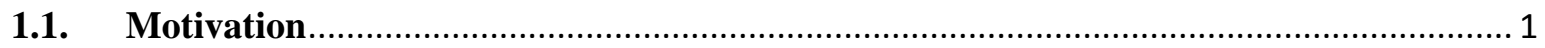

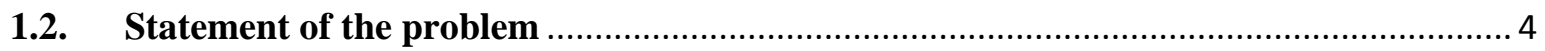

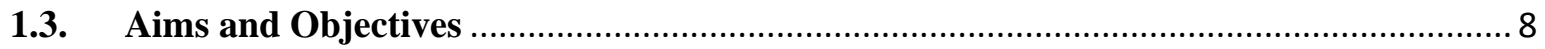

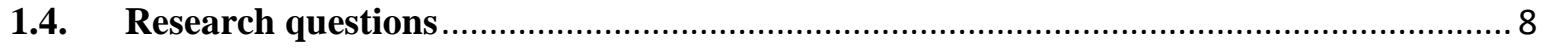

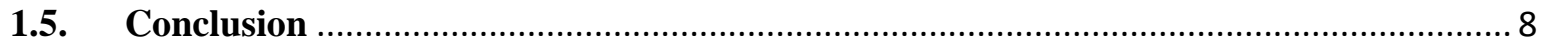

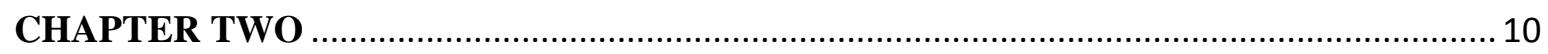

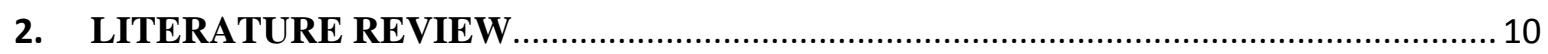

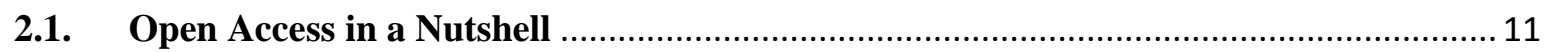

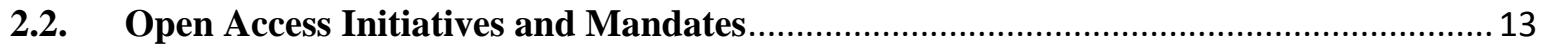

2.3. Open Access and the Legal Framework.................................................................. 16

2.4. Knowledge Sharing and Scholarly Communication ................................................ 18

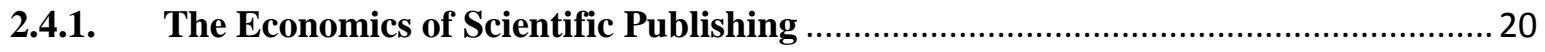

2.4.2. Open Access Scholarly Communication Models ……........................................... 22

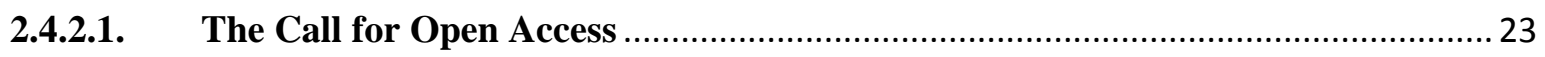

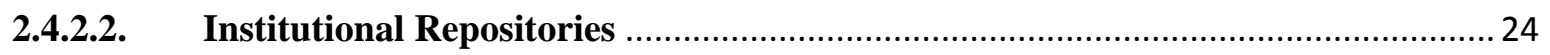

2.4.2.3. Role of Librarians in the Development and Maintenance of Institutional

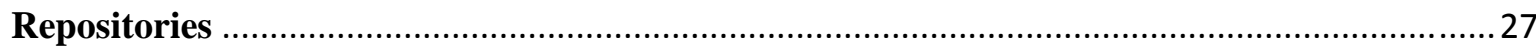

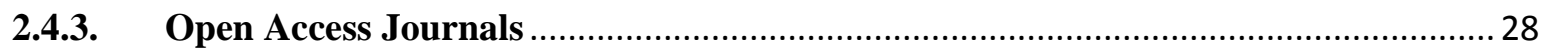

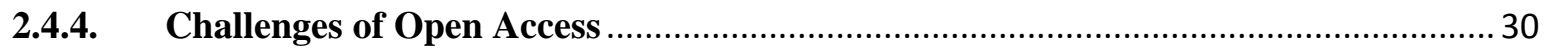

2.4.5. Open Access in Developing Countries.................................................................... 34

2.4.6. Barriers of Open Access in Developing Countries ................................................... 40

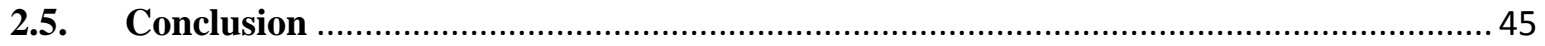

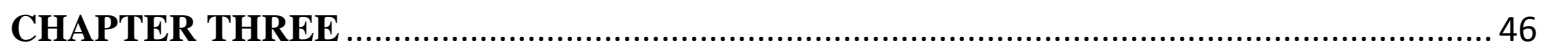

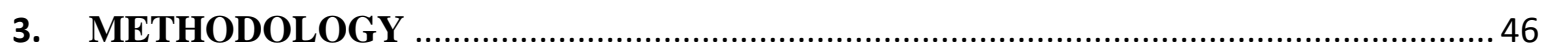


3.1. Case Study Method and Qualitative Analysis Technique ........................................ 46

3.2. Target population, Sampling and Data Collection................................................... 48

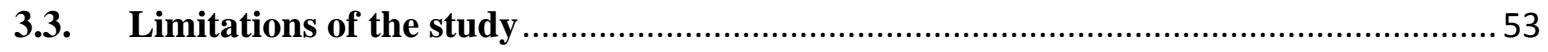

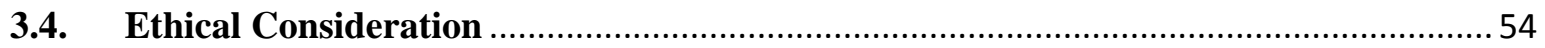

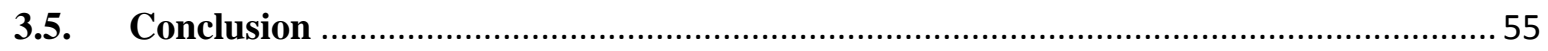

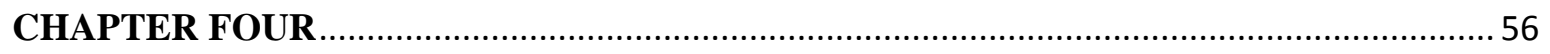

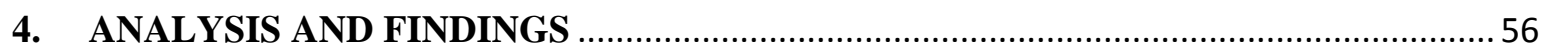

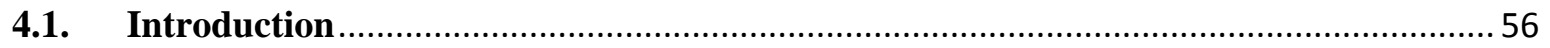

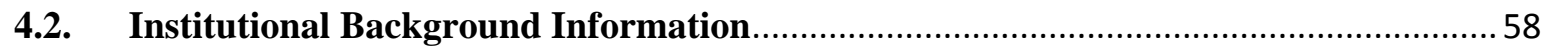

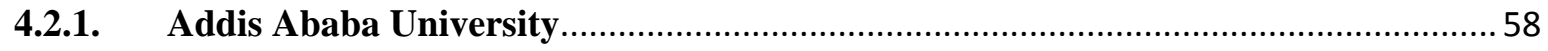

4.2.1.1. Addis Ababa University Research Institutes .........................................................59

4.2.1.2. Overhauling AAU's Research Dissemination Endeavor ...................................... 61

4.2.1.3. Addis Ababa University Library System ......................................................... 64

4.2.2. Ethiopian Ministry of Science and Technology (MoST) ........................................... 64

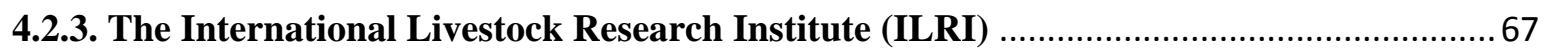

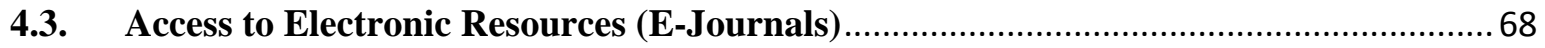

4.4. Dissemination of Ethiopian Research Output ……................................................... 71

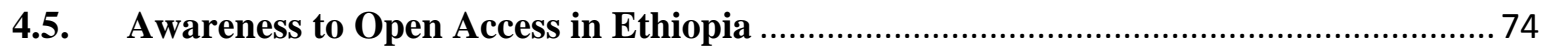

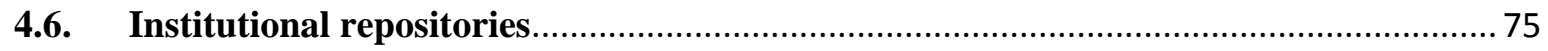

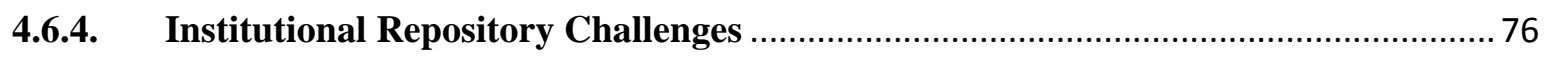

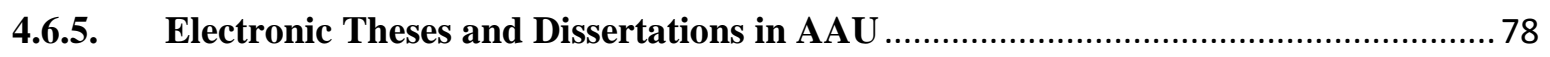

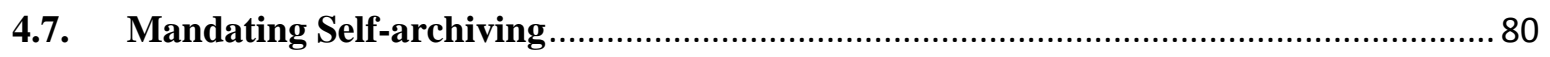

4.8. Open Access and Its Potential Benefits to Ethiopia ................................................. 81

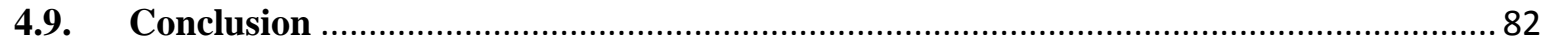

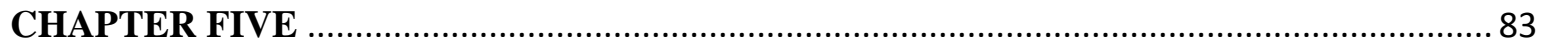

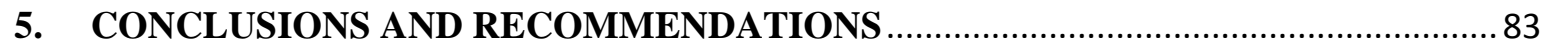


5.1. The Need to Change the Status Quo: Towards an Open Access Scholarly Communication Model for Ethiopia

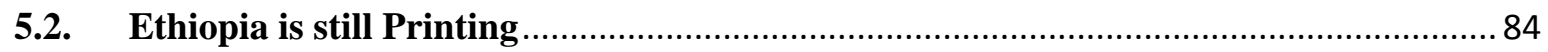

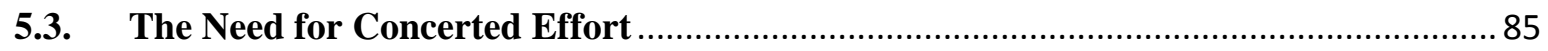

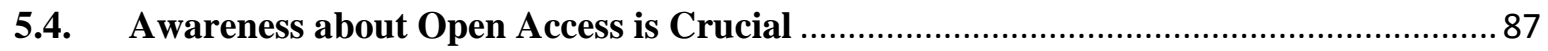

5.5. Institutional Repositories: Ethiopia’s Green Road to Open Access ..............................87

5.5.1. Mandating Self-archiving: the Prophylaxis against Zeno's Paralysis....................... 89

5.5.2. The Need for National and Institutional Open Access Policies....................................90

5.5.3. Use of Licenses in Institutional Repositories …….................................................. 90

5.5.4. Free and Open Source Institutional Repository Software .........................................91

5.5.5. Federation of Ethiopian Institutional Repositories................................................ 91

5.5.6. Institutional Repositories should be OAI-PMH Compatible .....................................92

5.6. Open Access Journals: The Golden Road towards Open Access To Ethiopian

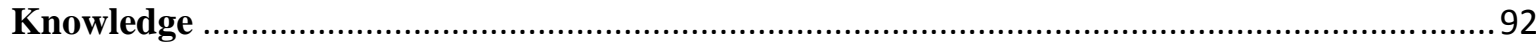

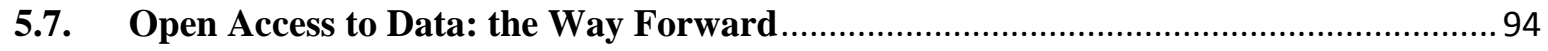

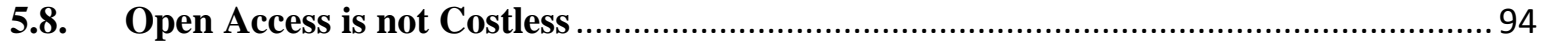

5.9. Practical Implications and Future Research …....................................................... 95

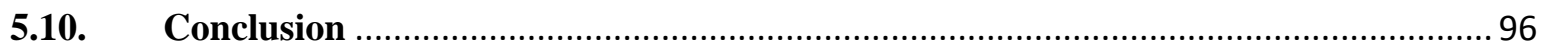

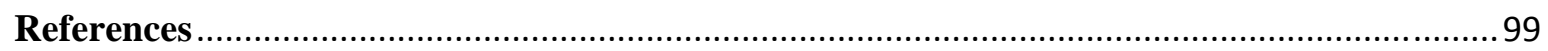

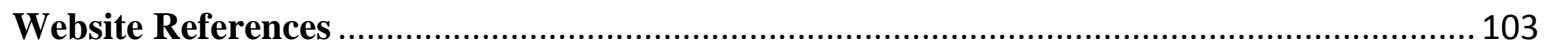

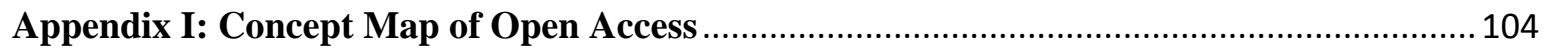

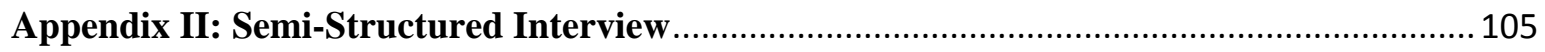




\section{List of Abbreviations}

AAU: Addis Ababa University

AGORA: Access to Global Online Research in Agriculture

AJOL: African Journals Online

BMJ: British Medical Journal

BOAI: Budapest Open Access Initiative

DOAJ: Directory of Open Access Journals

EDRI: Ethiopian Development Research Institute

eIFL.net: Electronic Information For Libraries

EJDR: Ethiopian Journal of Development Research

ETD: Electronic Theses and Dissertations

Fedora: Flexible Extensible Digital Object Repository Architecture

HINARI: Health InterNetwork Access to Research Initiative

ICT: Information and Communication Technology

IDR: Institute of Development Research

IES: Institute of Ethiopian Studies

IFLA: International Federation of Library Associations and Institutions

ILRI: International Livestock research Institute

INASP: international Network for the availability of Scientific Information

ITU: International telecommunication Union

JISC: Joint Information Systems Committee

JSTOR: Journal Storage

LRG: Local Research Grant

MoST: Ministry of Science and Technology

OA: Open Access

OAI: Open Archives Initiative

OAI-PMH: Open Archive Initiative Protocol for Metadata Harvesting 
OpenDOAR: Directory of Academic Open Access Repositories

OSI: Open Society Institute

PERI: Programme for the Enhancement of Research Information

R\&D: Research and Development

RCUK: Research Councils United Kingdom

RoMEO: Rights MEtadata for Open Archiving

SHERPA: Securing a Hybrid Environment for Research Preservation and Access

SPARC: Scholarly Publishing and Academic Resources Coalition 



\section{CHAPTER ONE}

\section{INTRODUCTION}

This chapter introduces the thesis with information on what motivates the research topic, statement of the problem, aims and objectives and research questions. The motivation sets the research context by providing a practical example of a law school in Ethiopia where faculty had no access to journals. The statement of the problem describes how knowledge prefers openness and collaboration, and how open access would help redress the poor access to scholarly literature in Ethiopia. The aims, objectives and research questions present the significance of the study.

\subsection{Motivation}

After graduating from university in 2001, I worked as a law librarian in Mekelle University, 780 kilometres from Addis Ababa. The university was one year old and the law faculty was yet to be inaugurated. It was challenging for me and my American supervisor to develop a new law library. There are few law books in Ethiopian book shops, and it remains impossible to purchase books online. The only law journal, the Ethiopian Law Journal, had ceased publication. After two years of work, we developed a collection of tens of thousands of books. Staff and students, however, could not readily access journal literature. Although we were provided with a trial access period to Westlaw and Lexis, both big US-based legal commercial databases, this did not last long.

The lack of access to up-to-date journal literature was not related solely to the recent establishment of the faculty: staff and students of the oldest law school in the country, Addis Ababa University Law Faculty, also did not have access to journals. No law school in the country has a webpage describing its major activities and course materials. At Mekelle Law Faculty, we chose not to subscribe to a journal for many reasons: firstly, Ethiopian law journals are not available; secondly, foreign journals are expensive; and thirdly, bandwidth problems preclude the possibility of downloading articles in PDF format.

I worked for more than six years as a head university librarian and lecturer in Ethiopia, and thus I came in close contact with academic staff and librarians, and received feedback about the library services. Because of a wide range of economic and bureaucratic problems, the 
university libraries are not positioned to serve the ever-growing needs of the academic staff. When I was first employed, there were hardly any journals and, of these few, most subscriptions were terminated soon due to steep price increases. The universities simply cannot afford to subscribe to them.

When a non-for-profit organization called International Network for the Availability of Scientific Publications (INASP) based in Oxford, UK, started a project called Programme for the Enhancement of Research Information (INASP), I was contacted by the country coordinator of the Programme for the Enhancement of Research Information (PERI) project and was able to register for the e-journals and databases offered through this project, including EBSCO, Emerald Insight, Cambridge Journals, and African Journals Online (AJOL).

Although the range of e-journals and databases is limited, and there were persistent bandwidth problems, the ability to retrieve full-text versions of peer-reviewed research articles was an exciting phenomenon both for academic staff and the librarians. Other initiatives followed, such as The Essential Electronic Agricultural Library (TEEAL), Health InterNetwork Access to Research Initiative (HINARI), and Access to Global Online Research in Agriculture (AGORA). These are all projects that negotiate with subscription-based journals and enable developing countries' researchers access to scholarly articles at affordable prices.

The negotiating organizations (such as INASP) made it clear from the start that the benefiting institutions should prepare themselves to have an exit strategy so that they can have a sustainable, long-term access to the journals and databases. So, librarians from various institutions set up a consortium of Ethiopian university and research libraries in order to provide such a safe exit.

The continuing concern for most of us, however, was whether Ethiopian institutions could afford to subscribe to these rather very expensive journals and databases once these projects phased out. Administrators of universities and research institutions had even been reluctant to pay the small fees for staff training on the use of databases and electronic journals. While the consortium of Ethiopian University and Research Libraries has now been formed, the question that my colleagues and I kept asking was whether there were other viable means of 
access to scholarly articles, rather than subscribing to the still unaffordable databases and electronic journals through the consortium.

I attended a two week workshop in Trieste, Italy, from $7^{\text {th }}$ to $16^{\text {th }}$ July, 2008, entitled 'Using open access models for science dissemination', and this started me thinking about the potentials of open access to Ethiopia. The participants came from 36 different countries representing researchers, librarians, and practitioners. One of the workshops was 'Open access and developing countries', and the access problems mentioned above were discussed there, addressed by some of the pioneers in propagating open access.

During and after the workshop what came to my mind repeatedly was whether open access offers an opportunity to countries like Ethiopia to transform the current moribund scholarly communication system in the country. By October 2008, I had already started to communicate and discuss my interest to explore how open access can be best utilized in Africa specifically in Ethiopia.

Open access is not only about accessing journals that are published and made available elsewhere; it is also about self-archiving (in institutional and subject-based repositories) and publishing (open access journals). Studying the various types of open access scholarly communication models and investigating how it would affect developing countries like Ethiopia is, I believe, crucial, so that scholarly communication practices in Ethiopia can be transformed.

This research will illuminate the practicalities and procedures of how open access scholarly communication models could foster and support knowledge sharing and collaboration among Ethiopian researchers. Based on the literature review, interviews, and information obtained through observation, conclusions are drawn and recommendations put forward. The recommendations will delineate steps that can be taken by university academics and librarians in Ethiopia to best harness and contextualize open access initiatives to their needs. 


\subsection{Statement of the problem}

Mankind has made tremendous progress in both the discovery of knowledge and its sharing among its members. The fact that these two endeavours are mutually complementary and that each reinforces the other might seem evident nowadays. But this has not always been the case throughout the history of mankind. Arunachalam did not specifically provide any time reference, but one can surmise that perhaps what he is referring to is the time before the 16th and 17th century, when alchemy was the norm. Alchemists believed that everything evolves and transmutes itself in to something else. They believed that speeding up this evolution was crucial. For them, this could ultimately transform a stone to an ore, the ore to a metal, the metal to gold, the gold to a plant, the plant to an animal, the animal to a human being, and finally the human into a superhuman. To make this happen, the search for the discovery of the Red Stone, also known as the Philosophers Stone or the Elixir, was deemed essential and took paramount importance. For alchemists, the Elixir was the panacea to everything. Alchemy was a secretive art and was not supposed be shared with others, nor could it be shown to anybody else. Alchemists did not practice knowledge sharing; in fact apprentices were treated as janitors. ${ }^{1}$

In contrast to the philosophy of the alchemists, the technologists and physical scientists, who had emerged later on, based their theories and practices on scientific and empirical evidences, rather than spiritual power. This gave rise to a new era of knowledge discovery and the rebuttal of the long held assumptions and beliefs of the alchemists, including its dissemination. This can be observed when one looks at the life and works of Sir Isaac Newton, who was both an alchemist and a technologist. Newton used to share his knowledge through discussions with other scientist of the time and he was named as the "Last Renaissance Magus" as he spanned the two worlds (Stichweh, 2003). It is worth remembering that the saying "If I have seen further, it is by standing upon the shoulders of giants" is attributed to him.

\footnotetext{
${ }^{1}$ The Alchemists by Anders Sandberg, http://hem.bredband.net/arenamontanus/Mage/alchemy.html
} 
The technologists and scientists of the time believed that knowledge develops through sharing and collaboration. Stichweh (2003, p.3) contends that "it is a remarkable aspect of the scientific tradition that since the sixteenth/seventeenth century there arose no new schools or traditions in science which institutionalized a preference for the secrecy of knowledge”. Stichweh (2003) identifies universality and openness as preconditions for inclusion and popularisation of science. Universality indicates the temporal and special invariability of knowledge (for more on popularization and inclusion of science read full article of Stichweh, 2003). The second precondition is openness of science.

The following two sentences from Stichweh (2003, p.3) provide insights on how scientific knowledge should be universally accessible:

"If science can claim universality, especially social universality in the sense of presupposing validity of its truth claims for any individual whosoever in the world, then it follows with a certain consequence that access to these universal truths should not be denied to any one of those individuals for whom these truths are supposed to be valid on the first hand. And if openness is the only standard acceptable in dealing with scientific knowledge then again this openness should be realized for a public of maximum social extension”.

As a distinctive resource, knowledge favours openness and expands through use and re-use. As pointed out by Arunachalam (2008, p.7) “knowledge wants to be free”. In an earlier article, Arunachalam (2003, p.16) had stated that "The quest for exploring unknown territories - the loneliness of a long-distance runner - is the personal aspect. But aggregation and advancement of knowledge takes place by collective efforts of researchers around the world." This quest for sharing and openness in science in fact led to the flourishing of new disciplines, professional associations, and communities of practice in which all led to scientific discoveries and innovations. Most of these discoveries and findings have been communicated through journals, conference proceedings and other kinds of formal and informal communication outlets. Especially journals have served as a main means of scholarly communication mediums.

The history of journal publishing goes back to 1665 when Henry Oldenburg, the secretary of the Royal Society of London, began to compile and distribute the correspondences of members of the Society in a journal named "Philosophical Transactions of the Royal Society of London” (Willinsky, 2006; Swan, 2006; \& Solomon, 2008). Before 1665, scholars used to 
communicate using hand written letters and had to make a copy of each correspondence and distribute it to other scholars (Solomon, 2008).

From this modest beginning, the practice has blossomed to such an extent that currently there are more than 25,000 journals in which approximately 2.5 million articles are published per year (Dewatripont et al., 2006; Canessa \& Zennaro, 2008). Most of these journals are subscription-based (toll-access) where the reader or his/her institution has to pay a fee to access to the contents.

Exorbitant journal prices have forced academic institutions and libraries to cut journal subscriptions. The fact that while on one hand government and funding agencies are putting out tax-payers money as research grants and yet more money, from the same tax-payers, is being spent for subscription to the results emanating from the research, when it is published in toll-access or subscription-based journals seems paradoxical. On the other hand, libraries have become financially crippled to subscribe to the growing number of journals, each of which can only be accessed by paying exorbitant subscription fees.

Solomon (2008) claims that the serials crisis covers the time period from the 1970s to the present. It has left many researchers with diminished access to peer-review scholarly literature (Chang, 2006; Salo, 2008; Pappalardo, 2008). Open access was one of the proposes solutions to address this crisis.

The notion of open access, however, is closely related to the ideals of free access to information, an ideal that library associations such as the International Federation of Library Associations and Institutions (IFLA), individual libraries and librarians have been advocating over the centuries. Lor (2007, p.:193) writes that "libraries have been about open access for a long time”. By and large, libraries have been arguing for free access for a long time. Open access in its present form, however, is a recent phenomenon.

The transformational role of information and communication technology (ICT), the ubiquitous Web, the flourishing of Free and Open Source Software, the ideals of the Creative Commons (see www.creativecommons.org), the Wikipedia project, and proliferation of social networking Web portals have all contributed towards the quest for open access to scholarly literature. 
The definition of open access has been stipulated by the three declarations and/or initiatives commonly referred shortly as BBB or just the 3B. The declarations resulted from the three conventions that were held in Budapest, Hungary (the Budapest Open Access Initiative in 2001), in Bethesda, Maryland, USA (the Bethesda Statement on Open Access Publishing in 2003), and Berlin, Germany (The Berlin Declaration on Open Access to Knowledge in the Sciences and Humanities in 2003). Open access means free and permanent access to peerreviewed, academically purposeful content over the Internet and the freedom to use, copy, distribute and adapt that content with proper attribution. Open access increases freedom of speech and it keeps the copyright advantages of the author and safeguards the interests of the general public (Willinsky, 2006).

Researchers often invest a significant amount of time, energy, money and intellectual effort in producing knowledge. They forecast trends, create efficient and better working models, design systems and help to improve work and processes. They communicate their research results, inter alia, through conferences, seminars and journals. However, after having borne this entire burden, in order to publish their intellectual works in peer-reviewed journals, they have to transfer their copyright to the publisher (Swan, 2006). The goal of the authors mostly focuses on creating a meaningful impact with their research work and in return expecting intangible gains such as peer recognition, academic rewards and promotion. In this publishing model it is ironic that the knowledge creator, i.e. the author, "rarely benefits as the subscription fee usually remains the revenue of the publisher”(Glover, Webb \& Gleghorn, 2006, p.197) and "academic authors are interested primarily in wide dissemination of their publications and seek no direct financial reward”( Park and Qun, 2007, p. 57).

While the digital divide continues to widen, the disparity in access to scientific publications between scholars from developed and developing countries also continues to expand. Open access is claimed to be one of the solutions to bring scientists on a relatively equal footing in terms of access to knowledge. Hence according to this argument, researchers in developing countries can disseminate their findings and gain access to scholarly knowledge. Nonetheless, the question as to which open access scholarly model best suits these countries and how open access can be harnessed remains to be explored. 
There exists no research on open access in Ethiopia. The main impetus for this research came from two observations. First of all, Ethiopian universities suffer from acute shortage of access to scholarly research. Second, Ethiopian universities and research institutions especially those run by the government have lagged behind in terms of having an organized collection of their research results and publishing their research works. Ethiopia never had a single institutional repository until January 2009 when Addis Ababa University (AAU) has started publishing its Electronic Theses and Dissertation on D-space.

\subsection{Aims and Objectives}

This research seeks to investigate how open access scholarly communication models would improve the research uptake of Ethiopian researchers. In other words, the study aims at to find out the current status of scholarly communication models and investigates which models would best suit in the Ethiopian context.

The following are the objectives of this study:

- to identify the existing challenges of the existing scholarly communication model in Ethiopia;

- to investigate the awareness of researchers and librarians about open access;

- to recommend open access scholarly communication models that best suit the Ethiopian context.

\subsection{Research questions}

This study seeks to address the following research questions.

1. How would the use and dissemination of research be improved in Ethiopia via open access initiatives?

2. How would open access fosters collaboration and knowledge sharing among Ethiopian researchers?

\subsection{Conclusion}

As a new phenomenon in the scholarly communication arena, open access has attracted the attention of librarians, researchers, funding agencies and governments. The main aim of this research is to analyse the various open access strategies, models and contextualize these 
strategies and models to Ethiopian situations. The research problem was initiated with observations that were made about the current Ethiopian scholarly communication system.

The thesis for this study is that open access enables researchers in developing countries to access research produced elsewhere and disseminate and share their research findings, both locally and globally, hence fostering knowledge sharing and collaboration. The study investigates the specific benefits of open access for Ethiopian researchers. This study will help provide an insight on how open access be implemented in developing countries and investigates the specific benefits of open access to developing countries scholars. 


\section{CHAPTER TWO}

\section{LITERATURE REVIEW}

This chapter reviews literature on the domain of open access. Peer reviewed articles have been selected from Emerald and EBSCO Host databases. A simple search technique was applied using the phrases “open access”, “institutional repositories”, “self-archiving”, and “open access journals” and relevant articles were selected and reviewed. In addition books, book chapters, reports, organizational websites and blogs are also used for this review. A concept map which was built using the Cmaps software (see Appendix 1) was used to cover the major concepts of open access with special emphasis the two open access strategies (selfarchiving and open access journals). In this chapter, among other things, literature on the conceptual foundations of open access (OA), OA mandates, OA models, legal, social and technical issues and challenges, and how OA benefits developing countries are reviewed and discussed.

Some open access articles are open access themselves and are freely available on institutional archives though Google scholar and other search engines. The challenge was selecting relevant peer-reviewed ones from those which are not authoritative. Care has been taken to make sure that either the article is peer-reviewed or it is from the authors who are prolific writers and advocates of open access. Besides, attempt has also been made to incorporate differing and opposing points of view.

Theses and dissertations were also used as references for this paper. Regional and national project reports on the development of open access were also used to. It has been noted that there are only very few books written solely on "open access”. A search using the phrase "open access" on Amazon.com brings not more than six books which are directly related to open access scholarly communication models. All of these books were partly or whole read by the author of this paper.

Especially, the book entitled "Open Access: Key Strategic, Technical, and Economic Aspects” (Jacobs, 2006) has been used extensively in this thesis mainly because the contributors of this book are the major proponents of open access. This book is also 
considered as the major open access book. Paul Willinsky’s “The Access Principle: The Case for Open Access to Research and Scholarship” (Willinsky, 2006) is used especially to define what "access" means and also to provide the benefits of open access publishing and the various arguments that surround open access including opposition from publishers. A compendium of selected literature from open access authors, institutions which promote open access and also open source software developers for open access repositories and journals has been compiled in 2008 by Canessa and Zennaro (2008), entitled "Science Dissemination Using Open Access” and the book "Developing open access journals: a practical guide” (Solomon, 2008) are also reviewed in this paper.

Peter Suber's blog (http://www.earlham.edu/ peters/hometoc.htm) is considered very authoritative and informative in the domain of open access. His blog is used to provide definitions and basic descriptions of open access concepts. In addition, websites of the organizations involved in this study and also websites of the major open access declarations and initiatives are also used to support this study.

\subsection{Open Access in a Nutshell}

Willinsky (2006: pp.xii) contends that a "commitment to the value and quality of research carries with it a responsibility to extend the circulation of such work as far as possible and ideally to all who are interested in it and all who might profit by it”. Open access has evolved as a result of the challenges posed by the unsustainable nature of traditional scholarly communication model_(Guedon, 2006) and addresses the problem of access to scientific literature (Swan, 2006) and as the name implies, open access means free and unrestricted access to research results. The connotation of free in open access does not only refer to cost of access but also the freedom to use, copy, distribute, and adapt a scholarly work with proper attribution to creators. Open access refers to free and unconstrained access to full-text academic works (Park and Qun, 2007, p.57).

The spiralling journal price (Lor, 2007) that resulted the 'serials crisis' (Swan, 2006) is not the sole impetus for the open access movement. In addition, the opportunities presented by ICT in facilitating peer-review, web publishing and setting-up institutional archives hence reducing the marginal cost of presenting and disseminating scholarly articles and intensified the call for open access. 
In discussing about open access, it is important to bear in mind that open access is not cost free. Costs such as managing peer-review, copy-editing and proof-reading need to be covered by the institution providing open access (Terry and Kiley, 2006; Suber, 2007) It is even more essential to note that open access does not mean quality compromises and it does not also imply vanity publishing. The traditional quality assurance mechanisms such as peer-review need to be done (Park and Qun, 2007). Besides, open access does not violate copyright (Willinsky, 2006).

In his blog Suber (2007) defines open access as literature that "is digital, online, free of charge, and free of most copyright and licensing restrictions”. Pertaining access rights, OA can be categorized as (i) "gratis” OA where subscriptions, licensing fees and pay-per-view fees are removed. Some also call "gratis" OA as "weak OA". ${ }^{2}$ (ii) "Libre" OA is online digital literature that is free of charge and free of "unnecessary" copyright and licensing restrictions. This includes the right to re-use, modify, adapt, sell, and distribute. Some also call Libre OA as "strong OA" (Suber, 2007). ${ }^{3}$

With regard to the ways to achieve OA, it is categorized in to two. (a) Green OA means depositing articles in online repositories that are harvestable using Open Archives Initiative (OAI) protocols. The articles may not be in the final published form, and may not be freely available in final published form. OA archives or repositories do not perform peer review, but simply make their contents freely available to the world. (b) Gold OA means the journal itself provides immediate full-text online access at no charge, that is, the online version of the journal is funded by some means other than mandatory subscriptions. OA journals perform peer review and then make the approved contents freely available to the world. ${ }^{4}$ Besides, OA has the following major characteristics. ${ }^{5}$

\footnotetext{
${ }^{2}$ http://www.earlham.edu/ peters/fos/overview.htm; http://pln.palinet.org/wiki/index.php/Open_access_basics; http://www.youtube.com/watch?v=tStVPrOPSEQ

${ }^{3}$ ibid

${ }^{4}$ ibid

${ }^{5}$ ibid
} 
1. OA is compatible with copyright, peer review, revenue, preservation, prestige, careeradvancement, indexing, and other features and supportive services associated with conventional scholarly literature.

2. OA does not infringe author's copyrights as "the legal basis of OA is either the consent of the copyright holder or the public domain, usually the former";

3. OA focuses on works that authors do not expect payment. These works are called royalty-free literature. OA is mainly focuses on peer-reviewed scholarly articles and conference proceedings literature. Peter Suber calls Royalty-free literature is "the low-hanging fruit of OA”, however, OA may also be broaden to encompass any digital content including monographs, raw research data, images, and multi-media presentations.

4. OA uses the creative Commons (CC) License (read more on next section on open access and the legal framework).

In general, open access deals with free, digital, peer-reviewed scholarly literature using the web as a dissemination outlet. It is essential to note that open access is not self (vanity) publishing and also open access does not infringe the rights of authors instead stipulates that intellectual creators need to be attributed hence recommends to use alternative licenses such as the Creative Commons Licenses (for more on licenses see the section on Open Access and the Legal Framework (2.3).

\subsection{Open Access Initiatives and Mandates}

Open access in short means free and permanent access to peer-reviewed research results without barriers. Swan (2006, p.11) explained the 3B's definition as follows: “[Open access] means the provision of free, immediate (upon publication), permanent access to research results for anyone to use, download, copy, and distribute." However, the meaning of open access is not without ambiguities. The following are explanations and definitions given by the 3B declarations.

1. The Budapest Open Access Initiative (BOI): With the goal of freeing scholarly articles from unnecessary barriers and restrictions of access, the Open Society Initiative (OSI) held a meeting of scholars from different countries and disciplines form December 1-2, 2001 in Budapest, Hungary (OSI, 2002). 
Cognizant of the transformative role of the web on scholarly communication, and taking in to consideration that peer reviewed articles are given away by authors without expectation of payment, the BOI participants called for free and unrestricted access to peer-reviewed literature. The coined the phrase 'open access' and by open access they meant the right to freely "read, download, copy, distribute, print, search, or link to the full texts of these articles, crawl them for indexing, pass them as data to software, or use them for any other lawful purpose, without financial, legal, or technical barriers other than those inseparable from gaining access to the internet itself” (OSI, 2002). The Budapest Open Access Initiative's guiding principle states that "an old tradition and a new technology have converged to make possible an unprecedented public good" (BOAI, 2003) ${ }^{6}$. The old tradition refers to the willingness of scientists to give their scholarly articles without payment; new technology refers to the web; and the public good is the peer-reviewed journal literature. To achieve the goal of open access to scholarly journal literature, they recommend two complementary strategies: self-archiving and OA journals.

I. Self-Archiving: First, scholars need the tools and assistance to deposit their refereed journal articles in open electronic archives, a practice commonly called, selfarchiving. When these archives conform to standards created by the Open Archives Initiative, then search engines and other tools can treat the separate archives as one. Users then need not know which archives exist or where they are located in order to find and make use of their contents (OSI, 2002).

II. Open-access Journals: Second, scholars need the means to launch a new generation of journals committed to open access, and to help existing journals that elect to make the transition to open access. Because journal articles should be disseminated as widely as possible, these new journals will no longer invoke copyright to restrict access to and use of the material they publish. Instead they will use copyright and other tools to ensure permanent open access to all the articles they publish. Because price is a barrier to access, these new journals will not charge subscription or access fees, and will turn to other methods for covering their expenses (OSI, 2002).

\footnotetext{
${ }^{6}$ http://www.soros.org/openaccess/index.shtml
} 
2. The Bethesda Statement on Open Access Publishing. The Bethesda Statement on Open Access Publishing convened a meeting on April 11, 2003 at the headquarters of the Howard Hughes Medical Institute in Chevy Chase, Maryland and released a statement on June 20, 2003 which states that for a publication to be open access, it should fulfil the following two conditions (http://www.earlham.edu/ peters/fos/bethesda.htm accessed on Dec.10, 2008)

i. The author(s) and copyright holder(s) grant(s) to all users a free, irrevocable, worldwide, perpetual right of access to, and a license to copy, use, distribute, transmit and display the work publicly and to make and distribute derivative works, in any digital medium for any responsible purpose, subject to proper attribution of authorship, as well as the right to make small numbers of printed copies for their personal use.

ii. A complete version of the work and all supplemental materials, including a copy of the permission as stated above, in a suitable standard electronic format is deposited immediately upon initial publication in at least one online repository that is supported by an academic institution, scholarly society, government agency, or other wellestablished organization that seeks to enable open access, unrestricted distribution, interoperability, and long-term archiving (for the biomedical sciences, PubMed Central is such a repository).

3. The Berlin Declaration on Open Access to Knowledge in the Sciences and Humanities. Building up on previous initiatives, the conference in Berlin, Germany from Oct. 20 - 22, 2003, calls on open access not only to peer-reviewed scientific research results but also raw data and metadata, source materials, digital representations of pictorial and graphical materials and scholarly multimedia material (http://oa.mpg.de/openaccessberlin/berlindeclaration.html accessed on Dec. 10, 2008).

The three declarations (3B) complement each other and the later builds upon the former initiatives. There are however some differences among these initiatives. The BOAI for example does not stipulate how copy right owners can deal with their rights pertaining open access on to their works. The Bethesda Statement, however, specifies that copyrights holders can provide users with free, irrevocable, worldwide and perpetual rights. In addition, the Bethesda Statement stipulates the requirement for institutional repositories for long-term archiving. The Berlin declaration is more or less the same as the Bethesda statement however 
it encourages researchers to publish their work as per the OA recommendations and cultural heritage organizations to support open access. This declaration underscores the importance of ensuring quality and good scientific practice for OA works (Bailey, Jr, 2006).

Many universities, research institutions, and funding agencies signed one or more of the three declarations. Following the declarations, funding agencies such as the US National Health Institute (NHI), the Research Council UK (RCUK), and the Welcome Trust mandated open access to research produced with their funding sources (Cockerill, 2006). Many Western countries funding agencies and universities followed suit mandating the self-archiving of public-funded research.

\subsection{Open Access and the Legal Framework}

The toll-access scholarly communication model requires authors to pass all their rights to publishers (Willinsky, 2006; Arunachalam, 2008). Arguably, this limits the easy dissemination of scientific discoveries as there are a significant number of users who just cannot afford to pay. Besides this model also limits the authors as they need to seek permission for their own work. In his own words Arunachalam (2008, p.8) described this "as the copyright rests with the publisher, scientists who wrote the papers in the first place have to seek the permission of the publisher if they want to make multiple copies of their own papers for distribution to the students whom they teach, and to use figures, tables and parts of the text in their subsequent writing, say a review article or a chapter in a book”.

What Arunachalam (2008) and others such as (Willinsky, 2006 and Suber, 2007) argued is that the toll-access subscription model has greatly hindered the free flow of scholarly knowledge. Literature on open access claims that open access does not infringe copyright and they reject counter arguments that claim open access is against the interest of the public and creators of knowledge. Chang (2006, p.700) writes that "the operation of open access is under copyright protection. The author owns the copyright and can authorise the publisher to publish the paper on the internet and put the papers on his or her own web site”.

The Free and Open Source Software (FOSS) movement uses a license that promotes the free sharing, adaptation, distribution and use of computer programs. The GNU General Public 
License (GNU GPL or simply GPL) requires adapters/modifiers of the system to put the same license and conditions on works ${ }^{7}$

Malcontent with the restrictive nature of intellectual property rights, American lawyer Lawrence Lessig initiated the Creative Commons (CC) in 2001 (Schiltz, Vershraegen and Magnolo, 2005). Under the all-rights reserved regime of copyright, when right holders sign contracts with publishers they give away all their rights exclusively except their moral rights (the right to be cited). With the CC however, copyright holders can decide which rights to give away and which to maintain. The CC allows them to compose their own licenses or permission statements and attach them to their works (Willinsky, 2006; Möller, 2006; and Suber, 2007). In short, GPL was to open source software and CC is to open access scholarly literature.

Since open access is about scholarly literature that is either in the public domain or author give-away, its distribution and use is facilitated by the use of CC licenses. Open access content is either in the public domain or the copyright holder consented to make it open hence open access does not infringe the intellectual rights of creators (Suber, 2007). Open access initiatives encourage copyright holders to proactively engage themselves and attach appropriate CC licenses to their works so that users of the works know what to do with it.

Canessa and Zennaro (2008) list the following are six major licenses offered to creators who publish and disseminate their work under the CC license:

1. Attribution Non-commercial No Derivatives (by-nc-nd) provides the rights to distribute works with proper attribution. It prohibits adapting and using for commercial purposes.

2. Attribution Non-commercial Share Alike (by-nc-sa) cc)(1) (1) This is a noncomercial license but allows to dowload, copy, distrubite and even adapt(traslate, and modify) works. The new adapted works will carry the same license and the original creator should be attributed.

\footnotetext{
7 (http://en.wikipedia.org/wiki/GNU_General_Public_License accessed on March 11, 2009).
} 
3. Attribution Non-commercial (by-nc) (c) (i) () This is similar to license number 2 but it deos not require to carry the same license as the original work.

4. Attribution No Derivatives (by-nd) (c) $\odot$ () $९$ This license allows to dowload, copy, and plus commercial uses. But the should remain unchanged and the creator must be attributed.

5. Attribution Share Alike (by-sa) (c) (1) (2) this license is more like the FOSS GPL lisence. Copying, distrubting, and Modifying/adapting are alowed even for commercial purposes as long as they credit the orginal creators and the new modificaitons should carry the same license.

6. Attribution (by) @) $\underset{\mathrm{EY}}{(\mathbf{C}}$ It allows commercial use. It allows copying, distributing, and modifying/adapting . The onlyrequirement is attribution. This is the most of the accomodating licenses.

As also stipulated in the Bethesda Statement on OA, it is important that authors know about the alternative licenses such as the CC in addition to the traditional "all rights reserved" license. In addition librarians and users of OA literature should also know about these licenses so that they make informed decisions regarding intellectual property rights. More information on this can be obtained from the Creative Commons website (http://creativecommons.org/).

\subsection{Knowledge Sharing and Scholarly Communication}

According to Sietmann (2008) knowledge is created, inter alia, through science and scholarship. The exchange of ideas, the careful observation and study of existing works and the linking of ideas create new knowledge. Sietmann (2008) contends that any hindrance to the access and sharing of knowledge directly affects new insights, discoveries and developments. This therefore calls for pertinent formal and informal knowledge sharing mechanisms to channel it from creators to users. It also calls for a scholarly communication model where free flow of knowledge takes place.

Arunachalam (2008, p.7) exclaims that "knowledge wants to be free!" Knowledge creation cannot be achieved without a collaborative effort to build one form of knowledge on another. 
In science, Arunachalam (2008, p.7) writes that “no one can claim to be a self made man!” as the creation and development of new knowledge is based up on the works of others.

Scientific publishing accounts as one of the well established channels of knowledge sharing and diffusion (Dewatripont at al, 2006; Swan, 2006). Schauder (1994) and Meadows (1998) as cited in Correia and Teixeira (2005) described that scholars discussed ideas and research results and correspond letters that contain accounts of their findings since the seventeenth century. As the volume of these correspondences increased, they needed a more efficient system that would address their needs.

Willinsky (2006) affirms that there has never been a time scholars stopped seeking better ways of finding and sharing the knowledge. As the demand for collaboration and knowledge sharing among scientists grows, the number of journals has proportionally grown (Dewatripont at al., 2006). Investors saw business opportunities and started publishing journals and provide access through subscription to the academic and research community. The publishers not only have started introducing more journals on various disciplines but also started taking over the journals from the professional and learned societies (Arunachalam, 2008). The core STM (scientific, technical and medical) publishing market is estimated between USD 7 billion and USD 11 billion (Dewatripont at al., 2006).

Since the beginning of the scientific journal publishing, researchers have never expected royalties from their intellectual works. However, they "give away their journal articles in exchange for a host of intangible benefits, such as a time-stamp that gives them priority over other scientists working on the same problem, and the prestige, citations, and impact that advance their careers” (Canessa and Zennaro, 2008). Until the 1990s print journals were the predominant means of scholarly communication (Swan, 2006).

Scientific publishing has served academics and researchers significantly as medium of scholarly communication and many of the innovations and inventions in science are owed to this profound medium. However, as time goes by the existing publishing model (i.e the subscription model) has been found limiting especially when the dramatic increase in subscription charges. As a result new ways, new approaches and models were sought. The 
open access movement (see Chapter One: Open access in a nut shell for more on open access) is a result of such calls.

The open access publishing model like the subscription model entails cost. The following section discusses the economics of scientific publishing and the various publishing models.

\subsubsection{The Economics of Scientific Publishing}

The web has greatly helped to reduce the cost of publishing and dissemination. One of the arguments in the open access community is that commercial journal publishers have kept increasing the subscription fees even in the presence of reduction of publishing and dissemination costs. On the other hand, open access itself does not come freely. It involves cost. It is therefore imperative that the economics of open access scholarly communication model is analysed.

As mentioned by Dewatripont at al. (2006, pp.26-27) the following major trends have been observed in mid 1990s:

- the importance of scientific journals has further increased;

- the business model remains overwhelmingly reader/library-pay;

- the size of the largest publishers increases, mainly through mergers and acquisitions,

- Prices have kept increasing faster than inflation;

- Libraries and publishers making contracts for bundles of journals as one package (Big Deals) and consortia subscriptions.

Dewatripont at al. (2006) described the current scholarly publishing market as far away from 'ideal perfectly competitive private market' because of the following reasons:

- There exists public funding for the time of the authors and reviewers and public funding is involved in purchasing journals;

- Researchers, the producers of scientific output, are also consumers of scientific information, and the private and social values of publications may differ when the individual researcher behaves as an author or a reader;

- Authors and readers are not in direct contact: the market is intermediated. 
When journal publishing started, it was not meant to be a profit-oriented business and it was mainly run by learned societies and professional associations where they use journals to disseminate their researchers' findings and discoveries. As time goes on, the societies and professional associations rather passed the role of publishing to profit making businesses.

The publishing business is therefore not considered as a perfectly competitive market because of the three major reasons mentioned by Dewatripont at al. (2006). Publishers are not, as they are at times claiming, selling intellectual works which they themselves got freely from authors in exchange of intangibles. In actual terms what publishers sell is the added value in terms of facilitating the peer-review, editing, proof-reading, dissemination and also the investment on indexing, search and online interfaces for their journals and databases. Complementary to the above reasons is the fact that for a market to be perfectly competitive there needs to be enough suppliers of the same product which is not true in publishing. There is no substitute for the journals. There are very few journals aggregators which mean the market is owned by few actors. This might attribute to the high increase of journal prices. This makes the publishing business far from being perfectly competitive and hence leaving the publishing business to the capital market system perhaps is not good for science and scholarship as it means the steep price increases beyond inflation and library budgets force libraries cut journals subscriptions.

To support the arguments above, let us cite some factual data regarding journal prices. Since most of journal publishers are for-profit industries, they sell their journal articles to individual researchers and libraries. However, in period from 1975-1995 journal prices raised to 300\% beyond inflation and this period is referred as the 'serials crisis'. The crisis forced libraries to cut subscriptions. One of the reasons for the increase in price is that the for-profit journals had less circulation compared to the learned society journals such as the ones owned by university presses and professional associations. The assumption was that there exists a "reverse causality between prices and circulation" hence lower circulation journals led to increase in prices (Dewatripont at al. 2006, p.25).

Another reason which is worth mentioning here is the role of information and communication technology (ICT). As it eases the communication between reviewers and editors, authors and publishers, and as it has transformed the way scholarly ICT has brought the journal 
publishing cost down. Besides, ICT has brought new features and services such as crosslinking and citation analysis. The costs of publishing that are assumed to reduce using computers include printing, layout, mailing, filing, duplicating, postage, and other clerical support (Dewatripont at al. 2006; Willinsky, 2006).

The bottom line is if the economics of scientific publishing is not perfectly competitive, there is dissatisfaction either from the seller or buyers. In this case with the unjustifiable steep price increases, the major stakeholders of the model (funders, authors, readers and librarians) are negatively affected hence this kind of market called for an intervention from all stakeholders. This call resulted in the 3B declarations and initiatives (see chapter One) where these stakeholders expressed their voices and brought what we have today the open access movement.

In the road to open access to peer-reviewed literature, it is important to recognize the role of the various stakeholders of scholarly communication. This involves libraries, publishers, funding agencies, researchers, managers and the public. Collaboration and discussions among the stakeholders would provide a sustainable model that is best suited for the growth of science and knowledge.

In the following section, we will the alternative scholarly communication model that open access offers.

\subsubsection{Open Access Scholarly Communication Models}

Attributed to the factors mentioned in 2.4.1, open access was born out of intellectual discussions with a fundamental belief that knowledge favours openness. In this section, additional background about the impetus for open access is provided first, followed by the two major open access scholarly communication models; namely institutional repositories through self -archiving and open access journals.

It is important to bear in mind that open access has a very specific scope. It mainly deals online peer-reviewed literature. The online medium is chosen because of its cost reductions and the peer-review process ensures the quality of the work. Open access for example does not deal with books and music. It is because creators of such works expect payment/royalty 
for their works where as authors of journal articles do not expect the same. As indicated in chapter one, open access can be offered in two ways: through institutional repositories (which are set up by institutions to store, manage and make accessible institutionally produced research results (including peer-reviewed conference proceedings) and open access journals(setting-up and running an online journal which is free and open access). The first path to open access is what Suber $(2007)^{8}$ calls the low hanging fruit. Whereas the later, requires significant institutional commitment and resources hence it is considered the golden road but the long road to open access.

\subsubsection{The Call for Open Access}

Swan (2007) questions whether the current subscription-based scholarly communication model "aids the progress of science or gets in the way". Swan argues that the present system gets on the way to rapid access to scholarly research results with without barriers. According to Swan, especially developing countries researchers are hard hit by such a model.

Swan (2007) strongly contends that e-science coupled with the open access model brings disparate scientific efforts together which otherwise have been fenced and isolated with conventional boundaries of department, topic or discipline.

The traditional subscription-based scholarly publishing model has contributed greatly to serve scientists as a system for knowledge sharing and it went unchallenged from 1823 to the 1990s. A continuous price hike that is even higher than inflation rates put libraries in extreme pressure to cut journal subscriptions (Glover, Webb and Gleghorn, 2006, p.197). Various interested groups, mainly academics and librarians called for new methods of scholarly communication. Open access "has emerged in reaction to the unsustainable nature of the present economic model of scientific publishers” (Guedon, 2006, p.28).

Quoting economist John Houghton, Swan (2007) pointed out that opening up the access to scientific discoveries and research alone does not get society any farther as "science does not benefit in a vacuum", the premise however is that "enhanced access to research findings is

\footnotetext{
8 Suber, P. (2007). Open Access Overview Focusing on open access to peer-reviewed research articles and their preprints. http://www.earlham.edu/ peters/fos/overview.htm
} 
likely to result in an enhanced return on investment in research and development, something that can benefit every economy in the world.”

Arunachalam (2008, p.9) lists the following reasons which are considered an impetus for open access:

- Scholars and researchers have always been willing to share knowledge and are less interested to demand for royalties from their published articles;

- ICT and especially the web have enabled dissemination (distributing) electronic versions of articles much easier and less costly. Besides new technological applications such as data mining, grid computing, eScience and international collaboration in virtual space enabled collaboration and scientific undertakings easier;

- The price hike in journal prices forcing researchers to look for alternative ways of sustaining knowledge sharing.

Canessa and Zennaro (2008) also see the web as one of the factors that compel researchers to demand better ways of disseminating and access scholarly articles. The birth of the Internet in the beginning 1970, the development of graphical web browsers in the 1990s and the coming into existence of online discussion forums, webcasts, blogs, and wikis have all but transformed the way scholars disseminate their ideas and research results, access the works of others in near 'real time' (Swan, 2006).

The distinguishing factor for an open access model is that it should allow providing unrestricted access to published research (Cockerill, 2006). As mentioned in earlier part of the discussion, open access has two major paths: self-arching and OA journal publishing. Institutional repositories, disciplinary archives and sometimes author websites play are part of the self-archiving strategy of OA. The two major strategies of OA (self-archiving in institutional repositories and OA journal publishing) are discussed in the following sections.

\subsubsection{Institutional Repositories}

Repositories or archives would be organized around subjects (discipline-based repositories such as the http://arXiv.org) and institutional repositories (such as Tspace of the University of Toronto) (Jones, Andrew and MacColl, 2006). 
Lynch (2003) contends that institutional repositories are essential infrastructure to accelerate research and scholarly communication. Lynch (2003, p.2) defines university based institutional repositories as "a set of services that a university offers to the members of its community for the management and dissemination of digital materials created by the institution and its community members.” This definition can be contextualized to any context outside the university domain.

One essential point Lynch (2003) made is that institutional repositories requite a collaborative effort of librarians, information technologists, archives and records mangers, faculty, and university administrators and policymakers. Many universities and academic institutions have been developing institutional repositories and this development is getting momentum (Rockman, 2005). Institutional repositories include various kinds of digital objects including electronic theses and dissertations(ETD), e-prints (pre-and post-prints), learning objects, conference presentations and technical reports within an institution (Bailey, 2006). Institutional repositories in general main contain both peer-reviewed and non-peer-reviewed digital objects such as articles, reports, presentations, images, data, even multi-media items (Pickton and Barwick, 2006).

The primary goal of institutional repositories is to make the institution's intellectual product visible to users across the world through an interoperable and persistent online storage. To this end, institutional repositories use technical standards such as the Open Archive Initiative Protocol for Metadata Harvesting (OAI-PMH). This standard enables separate repositories be accessed and harvested (Pickton and Barwick, 2006).

The oldest, transformative and most cited e-print archive (subject-based repository) is the arXiv(http://arxiv.org) which was launched in 1991 by physicist Paul Ginsparg at Los Alamos National Laboratory. Ginsparg later moved with his archive to Cornell University. What makes arXiv transformative is that it has achieved near 100\% success in archiving eprints in selected areas of physic. Besides, the best practises from arXiv have been adopted by other institutions (Suber, 2006). Currently, the arXiv has 528,147 open access e-prints in 
Physics, Mathematics, Computer Science, Quantitative Biology, Quantitative Finance and Statistics. $^{9}$

As a discipline, physics enjoys a very open access culture. The biggest research institute CERN has adopted open access mandate to research that is done within and by support from CERN. CERN has developed an e-print software called the CERN Document Server (CDS). The software is distributed with the Free and Open Source Software License. CERN has also mandated self-archiving of all its researches to the CDS e-print server. These efforts made CERN a notable example in achieving open access (Guedon, 2006).

The PubMed Central database of the National Institute of Health is the biggest in providing full-text OA peer-reviewed journal articles in the domain of health and medicine 650,000 with full-text scholarly articles. The Cornell University’s arxiv.org repository has deposited 380,000 open access full-text documents (Jacso, 2006).

In 2005, for example, the United States National Health Institute (NHI) issued a policy demanding grantees to deposit their pre-prints in the National Library of Medicine's (NLM) PubMed Central (PMC) archive within 6 months of publication. RCUK, the Welcome Trust issued a similar self-archiving policy in 2005. In addition, the Welcome Trust concluded an OA agreement with Blackwell (Online Open), OUP (Oxford Open) and Springer (Open Choice). The Research Council UK (RCUK) also asked all its grantees to deposit their research outputs in an open repository immediately after publication (Glover, Webb and Gleghorn, 2006, p.197).

Self-archiving is what Peter Suber calls it the "low hanging fruit". That is to mean it is the easiest path to achieve open access. The ability to self-archive, however, is hinged on publisher's policies. With the success of open access initiatives, more and more publishers have been convinced to allow self-archiving by the authors of the articles. Some allow selfarchiving right away, others with embargos.

\footnotetext{
${ }^{9}$ http://arxiv.org/ accessed on March 18, 2009
} 
As shown in the SHERPA/ROMEO website (http://www.sherpa.ac.uk/romeo.php?all=yes) most publishers allow author-self archiving. There might, however, be some conditions that the publishers might require from the authors, for instance putting a hyperlink to the published article on the journal.

In fact the role of librarians in open access goes much more than advising authors in self archiving. The following section shows how librarian can play a proactive role in the management of institutional repositories.

\subsubsection{Role of Librarians in the Development and Maintenance of Institutional Repositories}

Librarians and libraries are at the forefronts in the provision of access to electronic resources to the academic communities. They study users' requirements, identify resources, solicit financial sources to buy these resources, liaise and negotiate with publishers, license subscriptions, organize information objects, and provide services. Librarians, inter alia, offer information literacy trainings to faculty and students.

Librarians are the major actors in the open access initiative simply because they complained about the ever increasing journals prices. The serials crisis was brought to the attention of university managers and researchers through librarians. This in effect brought the open access movement.

Rockman (2005) argues that libraries have seen their roles as collection developers diminishing with the adoption of institutional repositories as authors of intellectual works themselves depositing their works and creating metadata for it. However, as indicated by Steele (2006) a great deal of researchers are even unaware of the existence of institutional repositories within their universities. Librarians should not only bring awareness about such repositories but also they should still play their traditional roles of intermediaries; in this case between researchers and institutional repositories.

Many researchers are unaware of publisher self-archiving policies hence they are reluctant to cooperate to deposit their works in the repositories in fear of copyright infringement. Some 
hesitate to deposit their works in fear of plagiarism (Steele, 2006). This according to Steele calls for libraries to advocate and create awareness to their research communities about institutional repositories and related issues such as copyright, and how to check publisher policies.

Salo (2008) evaluated the status of institutional repositories and the challenges in his rather provocative article entitled "Innkeeper at the Roach Motel". The "build it and they will come” approach, Salo (2008, p.1) writes that, is doomed to fail and librarians are not adequately trained to assume the responsibilities of managing institutional repositories and they lack the motivation from their managers and even OA proponents. Salo (2008) criticizes the exclusion of librarians from the OA movement and the roles they should play are not mentioned in many OA books such as John Willinsky's the Access Principle. According to Salo (2008, p.7) this exclusion invites "the bizarre conclusion that libraries are not strategically, technically, or economically important to open access”.

Salo (2008) strongly believes that the current institutional repositories by the majority of universities do not involve librarians and librarians are not ready for the job. Salo wrote that "Librarians are therefore less active than might be desired in using and promoting repositories and cross-repository search engines.” (p.7). The road to open access journals is gradual as librarians do not change their behaviour overnight as they are accustomed to the toll-access journals (Cockerill, 2007).

Many institutions do not have proper plans for open access and institutional repositories. Salo (2008) suggests that OA as a model should be clearly presented to senior management so that they can assess where their institution stands comparing to other academic institutions in the world.

\subsubsection{Open Access Journals}

As stipulated in the $3 \mathrm{~B}$ declarations, open access is the goal and the two strategies to achieve this goal are self-archiving and open access journals. In 2.4.2 we have seen how selfarchiving significantly transforms the knowledge sharing and collaboration and how it helps to maximize research impact through increased visibility. In this section, we will see how open access journals help achieve open access. 
Open access journals are much like the toll-access journals in terms of quality assurance (peer-review mechanisms), editorial policies, and cost to produce (Bailey, Jr., 2006). What makes them different is that they are free for readers and they may use Creative Commons (CC) Licenses (more on CC Licenses see section on Open Access and the Legal Framework).

OA journal publishing has also several models. They follow a similar perform peer-review mechanism with the traditional subscription-based journals. They incur cost. There communication medium is solely the web. The unique distinguishing feature of OA journals, however, is that they are free for readers (Cockerill, 2006).

Willinsky (2006, p. 212-213) categorised the OA journal model in to six different models: author fee, subsidized, dual-mode, delayed, partial, and per-capita access models. The 'author fee' model is at times confusing for authors. Because while most authors do not expect royalties/payments for their peer-reviewed articles, they do not want to pay either for publishing their articles. Terry and Kiley (2006) call this the funder pays model. The implication is that the author may not be directly required to pay but his/her institution or the funding agency pays usually to publish articles in toll-access journals so that they can be accessed freely by anyone. Different publishers charge different amounts for an article. For example, Blackwell: Online Open (£1250), Oxford University Press: Oxford Open (£1,500); Public Library of Science (£850), and Springer (£1,700) (Terry and Kiley, 2006, p.107). So in this model, the institutions do not run open access journals, instead use the traditional toll access journals but find a means to pay the initial publication fee.

The second open journal model is the subsidized model where subsidies are secured from donor institutions to run an online open access journal. First Monday (http://firstmonday.org) is such type of journal. The third type is dual mode where both print and online versions of the journal are published and the print becomes subscription-based hence generating revenue to support the free online open access journal. The fourth type is the delayed model. In this model, an embargo of a certain time period is levied so that subscription could be collected in order to recover the publishing costs. The partial model is about making free access to selected articles and the last type is the per-capita model which is opening up access to 
developing countries according to their level of GDP. HINARI and AGORA are good examples of this type of model.

In general the open access journals models (also called the Gold OA) are not cost-free and running a journal is a full time commitment for institutions hence it requires a strategic plan of action and allocation of resources. These models are however the fastest ways to achieve the goal of open access.

It is important to note again that self-archiving is the 'low hanging fruit' where it requires less resource commitment than running an open access journal. Nonetheless, financial, technical, and social challenges remain for both of the strategies. The next section discusses some of the open access challenges.

\subsubsection{Challenges of Open Access}

Open access has brought tremendous opportunities to institutions but also complex challenges. Organizations are required to institute new policies and change some of their cultures related to scholarly communication. Managers need to commit first their willingness and second resources to set up and maintain institutional repositories and open access journals. Librarians are challenged to re-think their journal acquisition strategies, learn new technologies, building and deciding on content for institutional archives, preservation techniques and providing services to the community of users within and outside the organization (Jones, 2007).

Though there has been evidence that self-archiving in institutional repositories by authors has not negatively affected the profit of publishers, there has been stiff resistance from publishers. The resistance also comes from the associations, universities and authors. But the reasons for this kind of resistance are mainly social and psychological. According to Harnad (2006), open access is entrenched by endless and ungrounded fear which Harnad (2006) dubbed it as “Zeno's paralysis”. The paralysis is the lack of action by institutions and their researchers causing the movement of open access to knowledge sluggish. 
While the arXiv.org has shown the possibility of achieving $100 \%$ open access, many institutional repositories are struggling to populate their repositories with content, mainly because the authors failed to do so.

Authors' role in self-archiving is a substantial one. Swan (2007) for example exclaims that few key strokes in front of the computer (include some metadata, and hit the submit button) would save the intellectual works from being obscure and inaccessible.

Harnad's 'Zeno’s Paralysis’ is coned “after the philosopher who worried, how can I possibly walk across the room? There isn't enough time! Before I can get across the room I first have to get half way across the room, and that takes time; but before I can get half way across the room, I have to get half of half way across the room; and so on. So there isn't the time even to get started; hence I can’t possibly walk across the room” (Harnad, 2006, p.78)

Researchers are wary of many issues pertaining depositing their articles in their institution's repositories. Harnad (2006) lists the many issues that are symptoms of the 'Zeno's Paralysis' that has made the way to $100 \%$ open access very slow. The following are some of the frustrations by researchers. and he argues these are mostly ungrounded fears (Harnad, 2006, p.79-84). Some think that self-archiving is illegal. This fear is not supported with cases of eprint submissions causing copyright war. From half a million physics articles which have been published in toll-access journals and archived to arXiv, less than .0001 percent has been removed because of copyright issues. Though open access does not mean compromising quality of research, many link peer-review only to subscription-based journals. In addition, authors do not have confidence in the prestige of open access publications and they fear that they may not get promotion by self-archiving.

Mandating self-archiving, Harnad believes, is the Prophylaxis against Zeno's Paralysis. Harnad (2006, p.78) puts it as follows “The pragmatic solution to Zeno's Paradox is of course to just go ahead and let your legs do the walking anyway. The cure for Zeno's Paralysis is the same, except it’s your fingers that need to do the walking”.

In addition to the social challenges, open access also faces technical challenges. Institutional repository software have not matured yet ( EPrints, DSpace and Fedora were released in the years 2000, 2002 and 2003 respectively) and these systems are often challenging for librarians and other institutional repository managers to install, configure, and use (Salo, 
2008). Institutional repository software should be open, interoperable, should be supported by a community of technically minded developers and users, provide authentication and authorization features, easily customizable, and allow archival and preservation of content Andrew and MacColl (2006). Perhaps, the common denominators of institutional repository software features are metadata, interoperability and harvesting. Metadata standards such as Dublin Core, MODS, METS, and MARC should be used in order to share digital objects, enable cross-searching and metadata harvesting. To this end, as Guedon (2006) and Jones, Andrew and MacColl (2006) recommend that OAI-PMH should be adopted in institutional repository systems to enable data sharing though metadata harvesting.

Guedon (2006) argues that the major challenge for institutions to setup and run open access journals is the lack of viable business plan. Another challenges pointed out by Guedon is the vociferous opposition of traditional and learned society publishers. Many, especially, from the side of the publishing industry were adamant in their opposition to the OA model. In his book, the Access Principle, Willinsky (2006) reflected on the following two critical comments from the publishing side. Rudy M. Baum, the editor of Chemical and Engineering News said the OA model is unproven and it is not in the interests of science. The solution to the serials crisis is the free market system itself. Willinsky (2006, p7) out rightly rejects the notion of free-market solution. He explains: "What sort of market drives subscription prices and cancellations up to the point of forcing libraries to cancel journals? What sort of market ensures that the labor invested by faculty authors and reviewers results in journals that their own libraries can no longer afford?”

Again from the publishing business side, Vitek Tracz, a member of BioMed Central Ltd., testified the following in front of the U.K. House of Commons Science and Technology Committee: "it is the scientists who do the research, who publish, who referee, who decide. Most of the referees are chosen by another scientist. This is a process run by scientists and for us publishers to presume that we have some major scientific role or influence is wrong.’’

In 2004, The U.K. House of Commons Science and Technology Committee asked the testimony of various stakeholders including publishers. John Jarvis, managing director of Wiley Europe, testified that OA is threat to the public and he said OA would lead to chaos. Jarvis continues saying that if you "speak to people in the medical profession, and they will 
say the last thing they want are people who may have illnesses reading this information, marching into surgeries and asking things'”. With this he mean access to medical information and knowledge would endanger the patients as they may prescribe medicine by themselves. Willinsky (2006) does not agree with this.

In Power Shift, Alvin Toffler (1990, p.7) writes that "Throughout the heyday of doctor dominance in America, physicians kept a tight choke-hold on medical knowledge. Prescriptions were written in Latin, providing the profession with a semi-secret code, as it were, which kept most patients in ignorance. Medical journals and texts were restricted to professional readers. Medical references were closed to the laity”. Toffler compares this with the today's access to medical and health information to patients in databases such as Index Medicus, Physician's desk Reference, cable networks technical programs on health, journals, and plethora of other sources of information that empowers the general patient (Toffler, 1990, p. 7).

Machlup (1984, p.159) cited in Willinsky (2006, p.9) describes access to knowledge as "a near-perfect public good. As a public, Machlup explains that, “to seek knowledge, to create, acquire, transmit, or retrieve knowledge”' entails costs, but that to use existing knowledge ... may be costless"'.

There are concerns from the side of publishers that open access will make them lose significant subscription revenue. One of the key influential figures in the OA movement, Harnad (2007), argues that even though there are hypothesised risks of losing subscription revenue, as a service industry, publishers need to adapt to "what is best for research and not vice versa”. According to Harnad(2007) “what is best for research, researchers, universities, research institutions, research funders, the $R \& D$ industry and the tax-paying public in the online age is: open access (free online access). That is what maximizes research usage and impact, productivity and progress.”

The Association of Learned and Professional Society Publishers' (ALPSP) lobbied to block the UK Research Funding Council's proposal to mandate self archiving of RCUK-funded research. The claim was that self-archiving would ruin journals. In 2006 Tim Berners-Lee, Stevan Harnad, Petter Suber and 11 other well-known personalities wrote a public reply to 
the RCUK rebutting the ALPSP's claims. While Berners-Lee et al (2006) gave a point by point rebuttal, their main argument was that "a policy that is undeniably beneficial to research and researchers, as well as to their institutions and the public that funds them. Publishers should collaborate with the research community to share the benefits of maximizing research access and impact.”

Organizations are already accustomed to the traditional scholarly communication model of journal publishing and they may not easily revert to open access models. When they do, they find it challenging to change their traditional established practises such as promotion criteria to accommodate the new realities. Voges (2008, p.81) reported that "there are already some examples of excellent Open Access journals that can boast considerable impact factors (e.g. New Journal of Physics, Journal of Cosmology and Astroparticle Physics, as well as the Open Access journals of the European Geosciences Union). However, their acceptance amongst scientists is still relatively low”.

The uptake of open access differs from discipline to discipline. In Europe for example, the science, technology and medicine are well ahead in implementing open access than the humanities (Gersmann, 2008, p.82).

In general, open access has been confronted with multitude of challenges. Some of them are mainly technical (hardware, software, and bandwidth). The social challenges are fairly complex. Researchers need to be convinced that open access benefits themselves and their peers. The fears mentioned by Harnad (2005) should be discussed openly on various formal and informal forums. Librarians have to take up the role of educating scientists about open access.

\subsubsection{Open Access in Developing Countries}

Only science, technology and research would alleviate the intertwined social and economical challenges of developing nations. De Beer (2005, p.3) contends that "knowledge diffusion and knowledge generation are at the heart of long term economic growth”. Access to knowledge and information that addresses local problems is critically essential. 
Developing countries researchers produce less knowledge and what they produce is not shared Arunachalam (2003). Bailey Jr. (2006, p.13) argues that "little wonder that even scholars at the richest universities in the world have difficulty accessing the specialized literature that they need, while those at the poorest barely have any access at all”. Many developing countries, especially Sub-Saharan African countries, have very limited access to scientific research results.

SARUA (2008) reported that Africa lacks access not only to content that is outside the region but also content that is created locally. Thus, it creates scarcity of knowledge. Ahmed (2007, p. 1) believes that African countries are facing a "scientific information famine" resulted from the knowledge divide. Among other things, this information famine is caused by lack of research and technological infrastructure and language problems. Researchers in developing countries lack scientific literature in their own local languages. Many scholars in developing countries write articles in English and publish them in English language journals. The great majority of the research will remain inaccessible for the local stakeholders who need to access the research works (Fung, 2008). Developing countries lack the appropriate channels to disseminate their research results and also to access research that has been conducted elsewhere which according to De Beer (2005) leads into s state of knowledge imperialism and knowledge dependence. As pointed out by Lor (2007) open access presents opportunities for developing countries to access and disseminate scientific knowledge between North-South spheres of the globe.

Many Sub-Saharan African universities and research institutions have not subscribed to scholarly journals as they cannot afford the increasing journal prices (Canessa and Zennaro, 2008). Nwagwu and Ahmed (2009, p.82) argue that open access encourages the scientific communities of Africa to disseminate their research findings and local knowledge globally. Ahmed explains that "[African] governments spend vast amounts on scientific research; yet, majority of the papers reporting the results of this valuable investment [are] locked in archives, which give access to paying subscribers only.”

With the recognition that research infrastructure and access to knowledge scientific knowledge in developing countries is severely limited. International projects were initiated to provide negotiated or reduced price to the major international journals. Such projects are 
Health Inter-Network Access to Research Initiative (HINARI), Access to Global Online Research in Agriculture (AGORA), International Network for the Availability of Scientific Publications (INASP) and World Health Organisation (WHO) Free Medical Journals Initiative are some of the major initiatives setup (Costa and Chan, 2005; Ahmed, 2007).

INASP/PERI and eIFL.net initiatives have been effective in negotiating with commercial journal publishers on behalf of low income countries. In addition, these initiatives organize trainings on the use of electronic resources, open access and use of the Internet (Costa and Chan, 2005). The eIFL-OA Program has three overarching goals. These are building a global network of Open repositories and Open Access journals, providing training and advice on Open Access policies and practices, and empowering library professionals, scientists and scholars, educators and students to become open access advocates. 10

While such reduced-price access initiatives have been recognized as significant interventions to alleviate the information poverty and knowledge gap between that existed between developed and developing countries researchers, but these initiatives lack the capacity to address infrastructural problems such as providing adequate bandwidth and access to computers (Costa and Chan, 2005; Ahmed, 2007).

Besides, these initiatives mainly focus on providing e-journals that are published elsewhere in the world and the effort to make local research works accessible has been minimal. Costa and Chan (2005, p.7) contend that "While north-to-south flow of research is valuable to the South in terms of up-to-date scientific development, South-to-South flow of knowledge is equally important”. Costa and Chan (2005) reported that the national and international initiatives lack coordination of efforts. Besides, the benefiting countries and institutions lack exit strategies once these projects have phased out. Nwagwu and Ahmed (2009, p.90) points out that "what Africa needs is an initiative or arrangement that will guarantee access of scientists to scientific publications irrespective of where the sources are developed.”

While PERI, HINARI, AGOA and related initiatives have contributed to bring awareness about e-journals and electronic publishing in developing countries and providing access to

${ }^{10}$ http://www.eifl.net/cps/sections/services/eifl-oa 
journals, they are not sustainable as they are based on funds from donors. In addition, they are limited by capacity to reach wide areas. Open access is a viable alternative that can be taken up by developing countries themselves with initial support from international funding agencies.

Canessa and Zennaro (2008) argue that OA has two major purposes for developing countries researchers. First, by storing their works on institutional repositories, the research results will be visible. Second, developing countries can access to a wide variety of research results through open access journals and institutional archives. Costa and Chan (2005, p.11-12) listed the benefits of institutional repositories to researchers in developing countries as follows:

- By showcasing their faculty’s research output, institutional archives will bring prestige to both the staff and the institution;

- Institutional access to research output;

- Improved citation and research impact;

- Use of Open source software and low infrastructure cost;

- Improved access to primary data.

Literature on open access shows that the uptake of open access by developing countries has been very low. There are very few open access journals in developing countries. In Africa, South African universities have been proactively involving in open access initiatives. South African universities have developed ETDs, institutional repositories and very recently some subscription journals are converting their models to open access.

The Southern African Regional Universities Association (SARUA) has studied the existing scholarly communication system of Southern African Countries and came up with recommendations on the adoption of Vision for Open Knowledge in Southern African Universities and the establishment of a research publishing and dissemination platform. The following are some of the main visions of the association (SARUA, 2008):

- Develop open knowledge sharing practices;

- Utilize under used knowledge through open education, open access and open research models; 
- Support the establishment open access journals;

- Support the establishment of systems for peer review of open educational resources;

- Develop reward and incentive mechanisms for those who contribute their works as open access;

- Establish scholarly communications as strategic functions of universities;

- Establish systems that enable universities to recognise and record all scholarly communications;

- Establish systems which enable scholars and universities to track the developmental and impact of scholarly communications.

One of the successful OA projects is SciELO - Scientific Electronic Library Online. SciELO is a model for cooperative electronic publishing of scientific journals for developing country researchers mainly in Latin America and the Caribbean countries.

Another important initiative that was started in Brazil is the Bioline International. Bioline is a not-for-profit initiative to provide open access to journals published in developing countries (Costa and Chan, 2005). Funded by international organizations including the Open Society Institute, UNESCO, and the International Network for the Availability of Scientific Publications (INASP), Bioline International benefits researchers across the developing world to narrow the knowledge gap that has been created due to the lack of scholarly communication outlets. The main objectives of Bioline are content delivery service, technical development, research on the efficacy of open access dissemination and library usage, as well as in education and training. ${ }^{11}$

Latin American countries especially Brazil has been active in open access initiatives. This can be seen from the launch of OA journals, archives and also OA conferences. The International seminar on Open Access for Developing in Salvador, Brazil, was held from September 21-22, 2005. The seminar resulted in what is called the "Salvador Declaration on Open Access: the Developing World Perspective”. The declaration noted that "Open access must facilitate developing countries' active participation in the worldwide exchange of scientific information, including free access to the heritage of scientific knowledge, effective

${ }^{11}$ http://www.bioline.org.br/info?id=bioline\&doc=about 
participation in the process of generation and dissemination of knowledge, and strengthening the coverage of topics of direct relevance to developing countries"(Salvador Declaration on Open Access: the developing world perspective, 2005).

In China, Qiji.cn was the first open access e-print archive. Qiji was set up in 2003 and was not affiliated to any institution. It was initiated by young volunteers in then filed of physics, computer science and medicine. Another pre-print archive is the Chinese Preprint Service System (http://prep.istic.ac.cn), Science paper Online (www.paper.edu.cn), and the alliance of open access journals (OAJs). The major challenges of OA in China have been the quality of the submitted papers, lack of funding, and copyright constraints. Besides, lack of awareness by scientists and librarians, and Publishers resistance and opposition were also reported as problems facing OA in China (Fang and Zhu, 2006). As remedial to these challenges, it was recommended that libraries need to be pro-active engaged in promoting OA and help their institutions set up institutional archives, training users, studying impacts of OA, maintaining quality of OA papers, collecting, integrating and providing OA resources on their website (Fang and Zhu, 2006).

Sahu and Parmar (2006) reported that India leads other developing countries in the number of scientific journals. The journals are published by learned societies and associations and members get a free print copy of a journal. The publishers charge non-members a subscription fee. Unfortunately, most of these journals suffer from low visibility and low circulation as access is hampered by subscription charges. Open access is believed to address these challenges hence to improve the circulation and impact factor of the journals (Sahu and Parmar, 2006). The Indian Academy of Sciences and Medknow Publications provide free online access to their journals (Costa and Chan, 2005).

As mentioned in the beginning of this chapter, open access has two strategies: OA journals and institutional archives/repositories. Albeit very low compared to developed countries, developing countries scholars produce research outputs that is of benefit to their local needs and also to the world at large. However, the visibility of these researches is very low. Open access has not made significant inroads in to these countries hence the number of OA journals and institutional archives is very low. This can be seen with the small number of institutional repositories that are registered by the major online directories. The Repository 
66.org ${ }^{12}$ shows that Africa has few repositories and those are mainly located in South Africa and Egypt. The map is a mashup of data from ROAR(registry of open access repositories) and OpenDOAR(directory of academic open access repositories)

The OpenDOAR which also lists open access repositories shows that from a total list of 1300 repositories distributed across the world, the whole of Africa has only 24. This means that Africa accounts only less than $2 \%$ of the total number of repositories in the world. While Europe accounts $48 \%$ of the repositories, Asia has only 11\% (OpenDOAR, 2009). ${ }^{13}$

\subsubsection{Barriers of Open Access in Developing Countries}

Open access in developing countries is still in its infancy. The low OA uptake is attributed to both social and infrastructural factors. Lack of awareness about open access, absence of incentives for librarians and researchers, poor Internet bandwidth, and lack of information literacy skills are some of the reasons for the absence of open access institutional repositories. Costa and Chan (2005) pointed out that researchers and managers from developing countries are concerned that their research results will be exploited by rich countries without recognition. Hence, they are reluctant to put their research results, theses and dissertations, datasets and other research reports online on open access archives. Another reason mentioned by Costa and Chan is the fear of publisher copyright violation. Authors fear that if they selfarchive the articles which were published on toll-access journals they think that this should compromise publisher benefits hence they afraid infringing copyright of the publishers (see the section above on Zeno's paralysis for such ungrounded fears and concerns). In addition, lack of institutional policy is mentioned as a barrier to open access in developing countries (Costa and Chan, 2005).

In addition to the social challenges, ICT infrastructural challenges mainly low Internet bandwidth significantly hampers the uptake of OA. While there have been several attempts to

\footnotetext{
${ }^{12}$ http://maps.repository66.org/about accessed on April 3, 2009

${ }^{13}$ http://www.opendoar.org/ accessed on March 12, 2009
} 
narrow the digital divide, only few developing countries have shown notable improvements in terms of increasing the penetration rate in access to computers and bandwidth optimization. Some African countries are trying to adopt new ICT policies and building networking infrastructure including installation of fiber optics. Many Sub-Saharan African countries lack the technological infrastructure to receive and distribute online journals (Ahmed, 2007). Ahmed (2007, p.14) pointed out that "weak communication and social infrastructure not only block information flows in most SSA countries but ultimately stifle social and economic development”. Guedon (2006, p.. 37) emphasizes that without adequate Internet bandwidth and digitization "Africa could not even hope to gain access to the scientific literature of the world at some in the not too distant future”.

OA is about content, specifically to peer-reviewed research works and the medium to get this content accessible is mainly the Internet. Developing countries are suffering to what many called the 'digital divide'. What OA has been addressing is rather the content/knowledge divide. So the question is how the digital divide can be addressed so that open access to knowledge is made possible.

Guedon (2009) argues connectivity and access to broadband Internet is crucial in order for the open access momentum achieve its visions. Hence to achieve the goal of OA, be it in the green or golden road, universities and research institutions in developing countries need to improve their bandwidth.

Three of the Open access declarations do not incorporate access to the Internet in their statements. Some for non-profit organizations who are involved in providing electronic resources in developing countries (such as INASP and eIFL.net), however, include issues such as bandwidth optimization, computer and Internet literacy, and electronic resources management into their requirements.

Open access relies on the availability of enough bandwidth to funnel the content the users. The initiatives to open up scholarly literature in developing countries have an insurmountable challenge to achieve their goals because of limited or no bandwidth in many parts of Africa. It is therefore crucial to look at the link between ICT and open access. 
Many African countries have recognized the need to put in place National Information and Communication Infrastructure Policies and implement it in various economical and social development strategies (African Union, 2006). World Summit of the Information Society held in Tunis in 2005, the Doha Action Plan (DAP) adopted by the World Telecommunication Development Conference (WTDC) in March 2006, and many other national and international conferences, summits and discussions helped African governments to commit their resources in ICT infrastructure (Kitaw, 2006). "A growing number of national and local governments are setting up national ICT policies, putting critical information online, automating administrative processes and interacting with their citizens through online services, yet the great opportunities offered by these new technologies remains largely unexploited.” (Kitaw, 2006, p.6).

The ITU reported that in the last 10 years, the world has seen continuous growth in telecommunications and ICT infrastructure and every year more and more people across the globe started using the Internet in order to access information. The number of mobile phone users has also increased over the years (ITU, 2009). These changes also affected developing countries positively. Though it is evident that the digital divide continues to exist, developing countries are committed to narrow this gap and governments are pursuing to improve the lives of the people and achieve the Millennium Development Goals through proper implementation of ICT.

"In the developing world, mobile phones have revolutionized telecommunication and have reached an estimated average 61 per cent penetration rate at the end of 2008 - from close to zero only ten years ago.”(ITU, 2009, p.11). The report showed that the growth of the Internet in developing countries is still low. Bandwidth in Africa is very limited. Though the developed world moved towards broadband Internet access, many African countries struggle with dial-up connection.”(ITU, 2009.

Africa registered fast mobile network growth from 1:50(1 mobile to 50 people) in the beginning of the century, to over one fourth of the population today. In 2007, less than 5 per cent of the population in Africa uses Internet, 14\% in Asia, 44 in Europe and America and $53 \%$ in Oceania (ITU, 2009) 
The ITU (2009) report underscored the important of bandwidth for developing countries to access online resources. Since Africa depends on foreign content that is produced elsewhere in English, French and Portuguese languages, users need more international bandwidth. The report also highlights the need for ICT skills to be able to benefit from it.

Taking into account ICT access, ICT use and ICT skills in 2007, the ITU's ICT Development Index chart puts Ethiopia at $147^{\text {th }}$ in the world where Sweden ranks $1^{\text {st }}$ and Niger the last $\left(154^{\text {th }}\right)$. In this report, South Africa ranks $87^{\text {th }}$ (ITU, 2009, pp. 32).

Hare (2007) reported that the changes that have taken place in Ethiopia over the last 10 years, show optimism that the country's ICT infrastructure will change albeit slowly. Hare however pointed out the fact that Ethiopia still has the lowest tele-densities in the world.

The country puts in place a national ICT policy and many public and private sector institutions are benefiting from the policy. There have been several initiatives to implement the national ICT policy. The major ones are the WeredaNet (to connect regional administrative councils and regional institutions) and the SchoolNet (connecting Ethiopian schools) (Hare, 2007).

The Ethiopia Information and Communication Technology Development Agency (EICTDA) attributes the low level of ICT development in Ethiopia to the following factors (EICTDA , 2008) ${ }^{14}$ :

- Underdeveloped physical and telecommunications infrastructure and limited numbers of both fixed and mobile Telephones and ;

- Lack of skilled expertise in ICT,

- High number of ICT illiterate public;

- Low Internet bandwidth;

- $\quad$ Low ICT market for ICT infrastructure;

- Undeveloped private sector;

${ }^{14}$ http://www.eictda.gov.et/Downloads/Policies/ICT_Policy_English.pdf 
- Lack of organized data and information resources;

- Legal and regulatory constraint.

The EICTDA also reported that the current distribution of ICT is uneven between big cities and towns. Most of the ICT development takes place in the capital. According to the report, in cognizant of the low ICT penetration in the country, the Ethiopian government has embarked in a wider scale of improving the ICT and telecom sector. Some of the notable projects include CT capacity building, Electronic government (woreda-net) and Electronic education (school-net) programs.

On a positive note, Ethiopia has now an ambitious national ICT policy that envisions to "improve the social and economic well being of the peoples of Ethiopia through the exploitation of the opportunities created by ICT for achieving rapid and sustainable socioeconomic development, and for sustaining a robust democratic system and good governance.” (EICTDA , 2008). One of the strategies of the government is to improve the availability and accessibility of local content and applications development. To bridge the digital divide, Ethiopia should intensify the installation of fiber optics cables, expansion of broadband Internet to universities, colleges, schools and also other governmental and private organizations. Only then can open access would be implemented to its full potential. This requires a concerted effort form all stakeholders including government, university management, researchers, librarians, funding agencies and NGOs.

The current status of the Ethiopian scholarly communication system and what the future holds for Ethiopian researchers will be discussed in chapter four. 


\subsection{Conclusion}

Open access has become a topic of scholarly discussion and has brought several cross-cutting issues in to the scholarly communication scene. The economic, legal, and technical issues are critical concerns in the uptake and implementation of open access models. Open access is implemented in several developed countries universities and research institutions. Institutional repositories and open access journals have been set-up. However, there are several challenges to implement open access in developing countries, especially in the SubSaharan countries.

In order to make progress in opening access to the scientific literature produced in developing countries and improve access to research produced elsewhere; the social and technological barriers of open access need to be addressed. This requires a concerted effort by researchers and managers of universities, funding agencies, national science and technology agencies, librarians, and IT people. Only then would OA would make visible and meaningful inroads to these countries hence "strengthen the science communities. 


\section{CHAPTER THREE}

\section{METHODOLOGY}

This chapter explains the qualitative methodology, the unit of analysis, the target population and technique of data collection. It also explains the data collection procedures, the limitations and ethical considerations of the study.

\subsection{Case Study Method and Qualitative Analysis Technique}

This study adopts a qualitative approach using a case study method to investigate how open access would be best suited to developing countries context such as Ethiopia. A case study research method is employed in order to obtain information and understand the level of awareness about open access and explore how open access would improve the research uptake, collaboration and knowledge sharing among researchers in Ethiopia. According to Yin (2003) case study is a preferred strategy to address the how and why research questions. A case study is a well-suited strategy to empirically investigate "contemporary phenomena" such as open access in the context of Ethiopian universities and research institutions.

The research problems such as how would the use and dissemination of research can be improved in Ethiopia through open access initiatives and how would open access fosters collaboration and knowledge sharing among Ethiopian researchers lend themselves for a case study research because of the need to answer the how and why questions. Observation and literature showed that there has been little or no effort made to implement open access in Ethiopia. Open access is therefore considered as a new phenomenon.

The study is qualitative because this approach suits best for a new phenomenon which has not penetrated the daily activities of subjects. If open accesses had been implemented, fully policies adopted, institutional repositories up and running, open access journals introduced, and if the technology of open access has become ubiquitous and enough awareness had been created; it would have been much easier to answer the research questions using quantitative research methods. It would have been for example to answer the number of articles submitted, accepted, published, the download rate, impact factor and type of software used, standards implemented, and related questions which would easily provide quantitative figures.

The unit of analysis: the unit of analysis in this case study is "open access". In this research, open access is assumed as contemporary a phenomenon that has been initiated by and for 
researchers, librarians, and funding agencies. Case study, as a research strategy, is best suited to investigate such interventions (Yin, 2003; Pickard, 2007). Semi-structured interview technique was chosen to collect data from researchers and librarians about open access within their respective institutions.

Experiences, qualifications and possible biases: Qualitative research and analysis is shaped by both the subject's and researchers' characteristics such as experiences, qualifications and even biases (Warden and Wong, 2007). The researcher of this study has been exposed to several discussions, workshops, lectures and readings about open access and its impact in research. There is a possible bias towards the benefit of open access to developing countries. One can notice that for example by reading the motivation and introduction section of this paper. In a case study approach, the investigator cannot be an outside observer. Instead, he/she is a team player. In such cases, biases are unavoidable. It is however apparent that the bias should not affect the result of the research significantly.

Interpretive: qualitative analysis is interpretive. In this research the unit of analysis is open access. Open access is considered as a phenomenon that would affect the subjects of this research who are mainly academic researchers and librarians working within a university or research institution context. In fact, whether open access has made significant effects or not, will be seen in this study. The subjects of the research and the researcher's interaction will create an interactive and iterative environment that will enable to collect enough evidences about the case.

The researcher contacted interviewees by phone and email to get clarifications on specific issues. In addition, websites and other literature was used to verify some of the issues that were mentioned in the process of the interview; for example, the availability of online publications, access to e-journals. The process also helped to verify the names of initiatives and projects.

Context: Warden and Wong (2007, p.6) argue that because of the context of a qualitative analysis, "meaning is tied to a specific setting and population and it will change over time". The questions asked for this research would bring a different answer over time ones for example a specific technology has changed or a new training has been offered about open access. The awareness of open access by researchers would certainly be different over the next year or so because of possible training interventions in that regard. 
Iterative process: Warden and Wong (2007) mention that qualitative analysis is iterative. In the context of this research, the researcher used such approach in order to verify facts or fill gaps that has been forgotten or uncovered during the initial investigation. According to Srivastava and Hopwood (2009, :p.1) argue that an iterative process or qualitative data analysis should be considered "not as a repetitive mechanical task but as a reflexive process, is key to sparking insight and developing meaning”. Hence, for Srivastava and Hopwood (2009) the visiting and re-visiting of the facts helps to verify it and also gain a new insight and helps to refine the focus of the research.

Additional meetings, phone calls, email exchanges were made. Websites were revisited to verify information that was vague during interview transcriptions and to provide more context to it hence gather meaning out of it. In some cases, these iterative processes were unsuccessful. For example, an email was sent to the AAU's ETD technical manager in order to find out additional information that was forgotten and also to verify some claims about the service. Unfortunately, it was not possible to find a reply to the email. However, a different mechanism was used to verify the information and the later was successful.

Pragmatic viewpoint: This research takes a pragmatic approach during the research question formulation, data collection and interview data analysis. The researcher working closely with university researchers and librarians learned that there is a dire need to improve the current scholarly communication system, especially developing and disseminating Ethiopian content. This research does not intend to find out truth about open access concepts and strategies. It will mainly focus whether the open access strategies and models work in the Ethiopian context. Reason (2003, p.1) writes that "the characteristic idea of philosophical pragmatism is that ideas and practices should be judged in terms of their usefulness, workability, and practicality and that these are the criteria of their truth, rightness and value. It is a perspective that stresses the priority of action over principles”.

\subsection{Target population, Sampling and Data Collection}

The researcher travelled to Addis Ababa, Ethiopia to conduct the interviews. The institutions under study have been also closely observed from December 23, 2008 to January 30, 2009. 
Researchers and librarians working in universities and research institutions were the targets of this case study. Snowball sampling technique was used to collect adequate information about open access in Ethiopia. Interview method was chosen to collect data from researchers and librarians about open access within their respective institutions. The interview method was therefore preferred from questionnaire as it provides richer information that may be arisen out of the face-to-face conversations.

The researcher has observed and read that open access in Ethiopia has not really been a focus of attention. Relatively however, the issue of e-journals has been raised and discussed by university and research librarians in Ethiopia. Addis Ababa University Library (AAULS) has been taking the initiatives to promote the use of electronic journals that have been made available through projects such as PERI, AGORA, and HINARI. These projects collaborated with journal publishers and aggregators to reduce the price of journals so that developing countries universities and research institutions would be able to afford to subscribe it to their researchers. Based on these observations and considering the fact that the awareness about open access is very low in the country, asking researchers and librarians what open access models and strategies they prefer, what kind of software they use for institutional repositories, and which open access journals they use to publish would only provide with limited or no relevant information for the research.

It was found difficult to make it a question and answer session as most interviewees barely know about open access issues hence the interviewer was rather convinced to change the approach and started to define and explain about open access: what open access is? How the open access initiative started? Then the interviewees started showing interest to talk about it and also to link it so something similar they know such as to e-journals and open source software.

Due to the non-existence of open access institutional repositories and open access journals it was difficult to provide interviewees with practical examples, in those cases the interviewer had to discuss hypothetically and with scenarios on what kinds of services and features an open access journal and institutional repository may offer. In such cases, the interviewees, would nod their heads with agreement and they would came to understand the issues of open access hence providing an opportunity how such a system would mean for them. In the 
course discussions, however, the interviewer managed to get the initial sets of questions answered, albeit, indirectly.

Interviewees were first contacted via email or telephone and asked to cooperate to share their views about open access to scholarly research in Ethiopia. Many were willing to share their views. Some hesitated that they know little or no about open access (most of these are academic researchers) and some suggested a better person who might give richer information. The consent of interviewees was asked in order to voice record the responses and discussions arisen out of the interview. All but one of the interviews was conducted in Amharic.

The evidence for this research comes from, 13 Ethiopian academics and librarians working in three academic and research institutions. On staff member of a funding agency was also included as an informant on how researchers are awarded with research grants and how the final product; the research work, is disseminated.

At the research proposal stage, only Addis Ababa University was selected for the study and the purpose was to interview two academic staff from four faculties within the main campus of AAU. When the investigator went to Addis Ababa, it was found important to include other research institutions. Besides, the initial focus was to interview more academic staff. During the preliminary observation, however, involving librarians was found essential as they are the ones who are directly working in projects and activities pertaining access to electronic resources such as INASP/PERI, HINARI, AGORA and related resources.

The researcher found out that eIFL.net and Addis Ababa University hosted a half-day workshop on December 22, 2008 Open Access: How to improve accessibility, visibility and impact of your research outputs for librarians and researchers. Contact was made by email and telephone with the workshop organizers and the list of participants was obtained. Most of the 42 participants were found to be librarians and information managers. The workshop organizer from Addis Ababa University was contacted in person in his office and the contact details of 42 workshop participants mainly librarians were obtained. Most of these librarians came from Addis Ababa University. Five of them came from the Addis Ababa campus of the International Livestock Research Institute. Librarians were contacted by telephone and also in person to solicit their willingness to cooperate to give interviews on issues of open access. 
The researchers/lecturers were also selected based on their experience in research or responsibility within the department, for example those who are editors of a publication.

This December workshop is the first open access workshop conducted in Ethiopia. The contact person was very cooperative in explaining about the nature of the workshop and also to give the list of the participants with their email addresses. Even though the first idea was to interview two librarians and 8 academic staff from Addis Ababa University, it has been found relevant to interview more librarians. In addition, it was found important to interview researchers and librarians not only from Addis Ababa University but also other research organizations which are assumed to have impact in influencing the research dissemination and access culture. These are Addis Ababa University, Ethiopian Development Research Institute, International Livestock Research Institute, and Science and Technology Commission.

Informants who could provide detail and richer information about the topic were chosen. Given the novelty of the concept and the lesser adoption of open access scholarly communication models in Ethiopia, it was not easy to find researchers who are well informed about open access. However, there have been quite good number of librarians in Addis Ababa who have been exposed to the half-day workshop on December 22, 2008.

In total, 4 librarians including the chief university librarian and 4 academic staff members (researchers) from Addis Ababa University; 1 from the International Livestock Research Institute InfoCentre; 2 staff members of Ethiopian Development Research Institute; and 2 Ethiopian academics writing their $\mathrm{PhD}$ thesis in the UK were interviewed.

The above informants come mainly from either of:

- AAU (the oldest and biggest university with 44,000 students);

- Ethiopian Ministry of Science and Technology(the biggest government funding agency for research and innovation projects);

- IDRI (the biggest government research institution on development issues); and

- ILRI (the largest branch of an international research institute). 
The information gathered from interviews, websites, reports and secondary sources from these mix of institutions is believed to be representative to inform about the Ethiopian scholarly communication systems.

Addis Ababa University (4 librarians +4 researchers): Addis Ababa University Library System has several branches in Addis Ababa. The chief university librarian, the ICT Librarian in charge of the ETD (Dspace), the head of Technology Campus Library (the contact person for eIFL.net on Open Access), and the head of the Medical Faculty Library were interviewed. These librarians have worked in AAU libraries throughout their career and they have also been involved in teaching undergraduate students. The information they provided also helped to validate what other researchers and librarians said about the access issues within the university.

Since open access is for researchers, it is important to involve the direct beneficiaries of such initiatives, hence, one lecturer from the Department of Psychology, one editor-in-chief of the Ethiopian Journal of Development Research (EJDR) and lecturer in the Institute of Development Research, one editor of the Ethiopian Law Journal and four other publications in the Faculty of Law, and one lecturer from the Faculty of Education who is doing a $\mathrm{PhD}$ abroad were selected as interviewees for this study. All but two of the interviews with AAU librarians and researchers were made from January 21 to January 23, 2009 based on prior appointments and all of them were conducted in interviewees' offices. One interview was made at AAU Medical Faculty on January 29, 2009.

One of the interviews was made in Istanbul, Turkey on February 2, 2009. This last interview was not initially planned, however, during an informal talk with a person who is affiliated to AAU and writing a $\mathrm{PhD}$ thesis in Europe, it has been found an important source of information.

Ethiopian Ministry of Science and Technology (1 staff member): It was learnt that part of the funding for research is obtained from the Ethiopian Ministry of Science and Technology hence it was found important to include the ministry within the study. The information that comes out of ministry's informants and its website would help to investigate how the organization ensures the proper dissemination of the research results to the intended purpose, mainly to the consumption of other researchers, the general public, and industries with in 
Ethiopia. The interview with the staff was conducted in January 29, 2009 at the office the interviewee.

The Ethiopian Development Research Institute (1 librarian and 1 researcher): It was learnt the researches that are investigated in this institute are used by the Ethiopian government for policy-related decisions. In order to see how the institute disseminates its research to researchers within and outside the country, one researcher (economist) and another librarian were selected for interview. Both interviews were held in the premises of EDRI on January 16, 2009.

The International Livestock Research Institute (1 staff member from the InfoCentre): while it was not possible to involve ILRI researchers due to time limitations, one staff member who works in the ILRI InfoCentre(the ILRI Library and Information center) and who knows about ILRI research dissemination systems including the publications, journals, intranet and the website was selected. The interview was conducted on January 16, 2009 in the office of the interviewee.

In addition, in order to obtain evidence on how respondents evaluate the scholarly communication system especially in relation to access to scholarly articles, two $\mathrm{PhD}$ candidates who have taught in a regional university in Ethiopia and now writing their dissertations in Europe are also selected for interview. The researcher met them while they were in Addis Ababa for data collection and vacation. The two interviews were conducted on January 17 and 19, 2009 in Addis Ababa.

In addition to these interviews, institutional documents were consulted in order to understand the mandates, operations and achievements of each institution. The website, if any, of each institution was accessed in order to assess how effectively the institution was utilizing the opportunities that the Internet offers in accomplishing its mandates, facilitating its operations and proclaiming its achievements. Searches were conducted, primarily using Google Scholar, in order to obtain a firsthand impression of the extent to which staffs in these institutions were being cited and referenced.

\subsection{Limitations of the study}

This study is about the role of open access for knowledge sharing and collaboration. It is believed that open access to scholarly literature leads to collaboration among scientists. 
However, the study does look only to open access concepts, initiatives, scholarly communication models and how these models suit to Ethiopian researchers. The study does not take the knowledge management approach of knowledge sharing hence issues such as researchers' knowledge sharing forums, communities of practice, peer-review mechanisms and other interactions are not covered in this study. The reader is therefore asked to extrapolate how open access fosters knowledge sharing and collaboration.

The literature review and analysis of this study does not look how open access brings impact. There exists no research on open access in Ethiopia and the OA research conducted in Africa very limited, hence supporting it with evidence from related literature on the topic was difficult.

Had it not been for time and resource constraints several cross-cutting issues related to the research culture of Ethiopian universities and scholarly communication systems would have been investigated in detail. Due to time constraints, it was not possible to include the regional universities and research institutions in Ethiopia.

Ethiopian universities and research institutions suffer from a multitude of challenges to access and disseminate scholarly research results. Some of these challenges are technical such as bandwidth, economical (budget constraints, low staff salary, poor incentive mechanisms) and others are mainly social (research culture). While each of these challenges demand a rigor empirical analysis, this paper only focuses on how these organizations should address some of the challenges to improve the access and visibility of Ethiopian research.

It would have been important to interview foreign scholars and/or libraries to solicit information on how difficult it is for them to get results of research done in Ethiopia. However, due to shortage of time, it was not possible to do so. Future research should do so to provide a clear picture of the research access and dissemination gaps.

\subsection{Ethical Consideration}

The purpose of the interview was described to the interviewees and they consented that their responses can be used in the context of this research. Consequently, the information obtained during interviewees and observation of AAU, EDRI, ILRI and MoST is used with proper care. During data analysis, the anonymity of the interviewees is maintained. 


\subsection{Conclusion}

The nature of the problem dictated the method for a qualitative methodology. A case study research method was chosen to investigate how open access would improve the scholarly communication system in Ethiopia. The researcher followed a pragmatic view point in attending to the research procedures and methodologies rather than a pure objective approach to find out possible 'truths' about open access.

Having worked in close proximity with researchers and librarians in Ethiopia, the researcher has observed scholarly communication problems especially in accessing journal literature and disseminating own research results and sought to investigate how open access would be implemented in the country hence recommend which open access models work in the Ethiopian context.

Following a pragmatic approach, the researcher opted for a discussion-based interview approach instead of a simple question and answer session with the interviewees. Since open access is a new concept to researchers and librarians, the researcher believed that, a question and answer interview technique would not have provided sufficient information for this research. 


\section{CHAPTER FOUR}

\section{ANALYSIS AND FINDINGS}

\subsection{Introduction}

In order to assess the awareness of researchers and librarians about open access and to find out how open access could foster knowledge sharing and collaboration among researchers in Ethiopia, two groups of respondents, mainly librarians and researchers, were identified from four major organizations which are, directly or indirectly, involved in research activities in the country, namely, Addis Ababa University, Ethiopian Development Research Institute, the International Livestock Research Institute, and the Ethiopian Ministry of Science and Technology. It is assumed that the mix of these organizations would adequately be representative of other educational and research institutions in the country. As this is a case study research, the reader would be advised to be cautious in generalizing its findings to all similar institutions to be found therein. The recommendations that will arise out of the research findings, however, are believed to be transferable to other institutions' contexts.

Addis Ababa University is the biggest and oldest university in the country. It has a diverse set of research programs and institutes. It publishes journals and aims to disseminate the findings that emanate from its research activities. The Ethiopian Economic Development Institute also happens to be the biggest research organization that provides input to government policy on economic issues. The third organization selected for this study is the Ethiopian Ministry of Science and Technology. Though the Ministry does not directly conduct research, it promotes research and innovation through the provision of research grants. The International Livestock Research Institute (ILRI) was chosen as an organization whose main purpose is conducting research and improving the livelihood of the farming communities in developing countries.

Though the purpose of this paper is not to evaluate websites of the concerned institutions, it is however felt important to point out the problems that have been encountered in the course of this study. Websites could and should also serve as research dissemination outlets, especially in the absence of institutional repositories and other indexing services. Besides, it was found out that there was a lack of attention to detail, in the design and management of the websites belonging to Ethiopian institutions of higher education. As websites play such an important role in promoting an institution's objectives and helping it reach potential stakeholders, 
mainly researchers who want to access research results in our case, it is deemed worthwhile to make their design, management, content as up-to-date as technology and finance permit.

The sections that follow will present more details on each of these selected institutions, with emphasis on the various scholarly communication models currently in practice therein, awareness about open access by both librarians, academicians/researchers. Furthermore, some issues that seem tangential ones from the perspective of open access initiatives, but which directly affect the future of open access scholarly communication models in Ethiopia are included. These so called tangential issues include the availability of broadband Internet, websites and technical expertise. Hence, the usefulness of the institutional websites will be touched upon, especially when these fall below what is achievable.

Before we delve into the details of the findings at each organization, it is deemed essential to point out the following points as each were prevalent throughout the organizations that were studied and hence were pertinent to the question at hand.

1. All the librarians involved in this study reported that their respective organizations have been involved with the INASP/PERI, HINARI, and AGORA initiatives, each of which provides access to electronic journals (which are subscribed at a negotiated price);

2. However, most held the opinion that access to research outputs conducted in Ethiopia is severely limited. As reported by them, it was only on rare occasions that libraries received hard copies of some issues of the publications emanating from research institutions within the country;

3. The responses from the interviewees, observation and literature show that the scholarly communication system in Ethiopia is very weak. The number of commercial and non-profit journal publishers is very few. Though universities and research institutions have visions and strategic plans to excel in development-oriented research work, the number of research results is very small. The research that has been produced does not reach the public and researchers elsewhere due to lack of dissemination outlets. 


\subsection{Institutional Background Information}

\subsubsection{Addis Ababa University}

Addis Ababa University (AAU) was established in 1950 and it is the oldest university in Ethiopia. The University used to be known as Addis Ababa University College but was named Haile Selassie I University in 1962. AAU awards Bachelors-, Masters- and PhD-level degrees in several fields. The University's mission is to "enlarge the nation's capacity in higher education [...] address urgent social problems in ways that promote the public good [Andreas Eshete, President, AAU].” 15

AAU began awarding M.Sc.-level (Graduate) degree programmes in 1978 and PhD-level ones in 1987(AAU, 2008). Gemeda (1996) reported during the period spanning 1980-1995, a total of 1474 post-graduate students have been graduated under the various faculties of the University. The number of graduates rose from 23 in 1980 to 189 in 1995 . Throughout these years, more than 900 theses and dissertations have been produced. On the other hand, Gemeda(1996) reported that lecturers had little time left for research as they are preoccupied with intensive teaching workloads.

AAU currently has an estimated student population of 44,000. This includes both those that are at the undergraduate, graduate and postgraduate levels. ${ }^{16}$ The University has expanded its postgraduate programs progressively over the years and is currently working towards achieving a national goal of producing 10,000 MA and 2,000 $\mathrm{PhD}$ graduates over a five- year period. To this end, it is transforming the processes involved in the postgraduate program so that it is in a position to accomplish this ambitious goal (AAU, 2008a) ${ }^{17}$.

\footnotetext{
${ }^{15}$ http://www.aau.edu.et/about/message.php, February 26, 2009.

16 AAU(2008b)http://www.aau.edu.et/AAUBPR\%20AS\%20IS/AsIs\%20of\%20the\%20Graduate\%20TeachingLearning\%20Business\%20Process\%20Reengineering\%20of\%20Addis\%20Ababa\%20University.pdf

17 AAU(2008a), “Teaching-Learning in Graduate Programs at AAU: report on the current As-Is situation” available at: http://www.aau.edu.et/AAUBPR\%20AS\%20IS/As-Is\%20of\%20the\%20Graduate\%20TeachingLearning\%20Business\%20Process\%20Reengineering\%20of\%20Addis\%20Ababa\%20University.pdf
} 


\subsubsection{Addis Ababa University Research Institutes}

In addition to being the oldest university in Ethiopia, AAU is also the oldest research institution in the country. The University has been a pioneer in several development-led research activities. Conducting scientific research and disseminating the results is considered as a major objective of AAU. Most academic staffs are engaged in research activities in addition to their teaching role. The University allocates research funds to research institutes, which are organized within the various faculties and departments. Among the major research institutes to be found there are:

- Institute for Development Research (IDR)

- Institute of Ethiopian Studies (IES)

- Institute of Educational Research (IER)

- Ethiopian Languages Research Center.

Most of these research institutes have websites where they provide information about the vision, goals, objective, major activities, research projects, announcements and other related information about themselves. Unfortunately, some of these websites appear poorly-designed and seem to be not well maintained. The information therein is not regularly updated and some links have been found to be broken and/or to be non-functional.

The Institute of Educational Research (IER): Established in 1968, IER has served as a research, documentation and publication centre of the AAU's Faculty of Education. IER gets its budget from the government. IER publishes the Ethiopian Journal of Education (EJE), as well as IER-Flambeau, a Workshop Proceedings series, and the IER Newsletter. Funds for publication purposes come from the Ethiopian Ministry of Science and Technology. The Institute also gets support from SIDA/SAREC, UNESCO/BREDA, USAID/BESO and the British Council, for organizing conferences and the dissemination of research findings. ${ }^{18}$

According to IER's website, the Ethiopian Journal of Education (EJE), published bi-annually, is the most reputable journal in the field of education in Ethiopia. Issued in English, the journal contains scholarly articles, book reviews, abstracts of dissertations, education-related

18 http://www.aau.edu.et/research/ier/eje.php 
news and updates. While IER distributes free print copies of the journal to selected Ethiopian institutions of higher education, including teacher training colleges and regional education offices, other organizations and individuals who wish to have access to the journal need to pay for a print subscription. Articles appearing in the journal are not available online on IER's website, in either abstract or full-text form. Nor are they hosted by any institutional/subject repository. EJE has not been indexed by African Journal Online (AJOL). ${ }^{19}$

The Institute of Development Research (IDR): IDR is a research institute within AAU and conducts development-oriented research that aims to alleviate poverty and foster development in the country. IDR focuses on multi-disciplinary research on topics as broad and diverse as rural development, food security, social development, natural resource development, and population-and-development. The Institute also awards offers postgraduate programmes in Demography, Development Studies, Environment \& Development, and Rural Livelihood \& Development.

IDR produces the Ethiopian Journal of Development Research (EJDR). At the time of this study, the EJDR could only be accessed through subscription. A single issue of the journal costs Ethiopian Birr 12.00 for individual subscribers and Birr 15.00 for institutions within the country. For those based outside Ethiopia, it costs U.S. \$20.00 per issue for individuals and US 25.00 for institutions. When accessed during the study period, IDR's website did not have any information regarding the journal. However, it was also discovered that the journal was among those being indexed by AJOL and, hence, abstracts of articles appearing therein could be accessed through this channel.

The Institute of Ethiopian Studies (IES): The IES was established in 1963. Located in the main campus of AAU, called Sidist Kilo, the Institute maintains a specialized library on Ethiopian collection, also known as the Ethnological Museum, a museum. The Institute has a long and successful record of hosting national and international conferences, on a multitude of topics. IES is an internationally recognized and successful institution. Its well-managed museum and library are renowned by scholars in the disciplines to which it caters.

19 http://www.aau.edu.et/research/ier/eje.php 
Since the time of its establishment, the IES biannually produces the Journal of Ethiopian Studies. The journal is a multi-lingual \& multi-disciplinary conduit, with contents appearing in English, Amharic and French. It is widely disseminated, both domestically and internationally. The journal is mainly available in print format and access is possible through subscriptions. ${ }^{20}$. Furthermore, the institute's other publications and conferences attract a wide variety of researchers from all over the world. Regrettably, at the time of this study, it had a very poor website that does not go hand in hand with the institute's well-earned reputation and image. A well designed and managed website could and should also provide information about IES's publications, including such items as to how and where to access the journal's current and former issues and when the next issue will be published. However, this did not happen to be the case, at least at the present time.

\subsubsection{Overhauling AAU's Research Dissemination Endeavor}

AAU is reported to have several problems in disseminating its research results. Gemeda (1996), for instance, reported that AAU's research is not development-oriented. In his own words, Gemeda (1996, p.236-237) writes that:

"It is obvious that our researchers should have their research projects geared towards the solution of the socio-economic problems prevailing in our country. However, we find that there are very few channels linking research to development. The technological or industrial base to absorb and apply graduate research results is weak".

AAU's management had recognized the need for transforming its research system that encompasses, focusing on initiatives that range from fund solicitation and resources allocation to the actual supervision of researches and the dissemination of results. To address this need, AAU constituted an eight member committee, known as the Business Process Reengineering (BPR) Task Force, in 2008 to investigate the causes of the University's researchrelated problems and to recommend improvements using BPR as a tool (AAU, 2008).

The findings of the Task Force indicated that research is an essential tool in creating a knowledge base, making the county's industries produce better, excelling in academic pursuits, and producing qualified graduates. In its objectives, the Task Force stated that:

\footnotetext{
${ }^{20}$ http://www.aau.edu.et/research/ies/jes.htm
} 
"Realizing the fact that there is a large bulk of research conducted and [that] there is also massive [amount of] research data collection at Addis Ababa University, the general public and the mushrooming industry in Ethiopia are not beneficiaries of these data in pushing forward the development of this country”(AAU, 2008,p.2).

The above statement indicates that it is a common understanding that AAU lacks proper channels to disseminate its research results.

The BPR Task Force also found that all research centers in the University did not have defined strategies for research dissemination. With the exception of a very few research institutes, for instance the IES which has published its journals for 18 consecutive years, many research centers and institutes perform their activities (organizing conferences, attending workshops, publishing journal articles, and conference proceedings) on an irregular basis and without any preset plans. This was mainly attributed to a lack of funds (AAU, 2008).

The Task Force mentioned the following reasons for the problems associated with research dissemination from AAU to Ethiopian industries and the general public(AAU, 2008):

- Inadequate communication outlets to disseminate research results to the general public, industries and other stakeholders;

- lack of commitment and interest from government officials and policy makers to attend AAU's conferences and paper presentations;

- The use of English for research reports and publications, which excludes the general public;

- When AAU researchers publish their works in international pay-access journals, their works remain inaccessible for the Ethiopian researchers and the general public;

- AAU publications are only in print format and they reach only few institutions;

- There are no internal seminars in all centers that could help in knowledge exchange between academic staff and improve research activities;

- The university has no complete record/database of conference attendees, paper presentations, travels of scientists in and out of the country to disseminate results;

- All centers are not open to the general public, even for one day in a year. 
In addition, AAU does not have institutional/subject repositories for outputs of the research conducted by either its staff or its research institutes.

Overall, the BPR Task Force found out that AAU is beset with a very poor research culture, an absence of clear research policy and strategies, non-existence of an incentive mechanism for researchers, a lack of research funds, and poor coordination. It was also noted that the University’s faculties and research institutes/centers did not even have a complete compiled list of research projects, leaving alone full-text copies of the research reports (AAU, 2008).

Furthermore, AAU is also overhauling its ICT Unit and another task force had also been constituted to study the existing system, by conducting what is known as an "As-Is" and "ToBe” analysis. In its report, the Task Force found out that the ICT services currently provided to university academic staff, students and to the whole university community was very poor. There happens to be a problem of very low bandwidth and the University's network was considered as being erratic. The report also mentioned that the websites of many departments included inaccurate and outdated information. The services were not properly supporting the teaching, learning and research activities of the University. According to this report, most of the operations at AAU are manual. The report concluded by emphasizing the urgent need to re-engineer the University's ICT Unit, so that the later could be in a position to support the goals of the University as well as the day-to-day and strategic functions of the university's community as a whole (AAU, 2008).

ICT has the potential to make tremendous contributions in streamlining research functions. Of course, adequate bandwidth is critical for research. Access to electronic resources by researchers and students could only be made possible through adequate bandwidth and reliable Internet connections.

From the observations made during this study, in the various departments of AAU including the library and academic staff offices, the process of checking emails took quite some time, leaving alone downloading full-text PDF articles form online journals and databases.

AAU is currently overhauling its research and development process through BPR. As can be read from the status reports, there are tremendous efforts put in place to implement the 
recommendations from the different taskforces. Speedy implementation of such overhauling initiatives are crucial for AAU, as the number of its education programs, size of the student population, and the number and variety of its research projects are increasing rapidly. In this research process overhaul, AAU should plan to develop new ways of research dissemination outlets, in order to effectively and efficiently be able to reach out its research stakeholders, mainly scholars and students, policy makers, industries and also anyone else, both within and outside across the country, who would be interested in AAU's research results.

\subsubsection{Addis Ababa University Library System}

University libraries in Ethiopia suffer from acute shortage of Library and Information Systems(LIS) professionals. As of 2001, AAU has changed the curriculum of the Bachelor in Library and Information Science into a Bachelor in Information Systems. This curriculum overhaul replaced the library oriented courses to more of computer programming and information systems. The introduction of ICT in most government institutions and better employability for computer graduates seems to be the major reason for this shift.

Hence the only LIS degree programme in Ethiopia has been closed. The graduates of the new program do not work in libraries as they hardly know anything about librarianship. This leaves libraries in academic and research institutions with a severe shortage of qualified information professionals. The absence of qualified professionals in the field negatively affects libraries' efforts to proactively take part in new initiatives such as open access. On hindsight, the closure of the BA- LIS degree program seems to be a regrettable one.

Relatively speaking, however, AAU's Library has well-qualified professionals, especially in comparison to other regional universities. The library houses an estimated collection of 500,000 books. The library gives 24 hours of service to campus resident students. It also provides internet services, mainly to post graduate students (Paiva, 2008).

\subsubsection{Ethiopian Ministry of Science and Technology (MoST)}

The Ethiopian Science and Technology Agency (ESTA) has been re-instituted and named the Ethiopian Ministry of Science and Technology. According to the organization's website (http://www.most.gov.et/), the Ministry has been re-instituted several times in the past and has undergone changes in its organization structure on a number of occasions. It was first established in 1975 as the Ethiopian Science and Technology Agency, then was re- 
established in March 1994 as the Ethiopian Science and Technology Commission, and very recently has been re-instituted as the Ethiopian Ministry of Science and technology.

The Ministry envisions contributing to the social and economic development of the country through the application of science and technology for sustainable social and economic development. It aims to build the capacity for an efficient, effective and sustainable national science and technology system through guidance, coordination and support to national S\& T activities that would enhance the socio-economic development of the country. The objectives of the Ministry are to enhance science and technology and initiate, organize and encourage research and development activities that enable the realization of the country's socioeconomic development objectives.

The following are some of the powers and duties of the Ministry, as entrusted to it by the government (http://www.most.gov.et/):

- Assist and encourage the establishment of associations that contribute to science and technology development and provide support for the publication and dissemination of science and technology papers prepared by professional associations;

- Encourage and ensure the application of studies, research and development activities carried out to improve and develop indigenous technologies;

- Establish a system for the collection of information on science and technology accomplishments, research work and results thereof;

- Keep a list of professionals and institutions that engage in research and development activities.

In line with its powers and duties, the Ministry has a Research and Development department and within this setup a Local Research and Development Grant (LRDG) programme. The main source of finance for LRDG is the Ethiopian Government. The money thus obtained is used to fund the research and development activities of young researchers, who must be affiliated to public institutions.

According to the interview conducted with an expert from the Ethiopian Ministry of Science and Technology, the organization's LRDG programme is a competitive funding scheme for young researchers throughout Ethiopia. Those proposals which are of scientific and national importance are chosen by a panel of experts. However, the Ministry has not been mandated 
with nor does it have any plan to ensure that the research findings and outputs that have been undertaken with its research grant are made available to public. Furthermore, The Ministry does not yet have an online repository system for storing, organizing, making available to users, or preserving for future use the said research findings \& outputs . However, a mandatory printed copy is collected from each researcher and this is put in a store within the organization. The said research papers are rarely put in the Ministry's rather small library. Furthermore, the Ministry does not yet have a properly designed website to inform the public and researchers its information regarding past-, present and planned research activities under its auspices.

The interviews and observation made indicate that, the Ethiopian Ministry of Science and Technology does not have proper channels for disseminating the research outputs that have been undertaken with its own funding. Neither is there a single repository that has been put in place to date; nor has a plan been made for one in the future. The Ministry is however currently in the process of designing a database of patents that have been recognized and registered with it.

There are no journals produced by the Ministry on a regular basis. Given its mandate to serve as the main catalyst of science and technology transfer in the country, it is perhaps unexpected to see that the Ministry does not have a single publication to disseminate the research results which emanate from its own funding. However, as the link http://www.most.gov.et/Publications.htm, found on the organizations website when last checked on 26 February 2009, seems to indicate, things might be changing for the better as it announce that "publication [are] coming soon".

According to the interview conducted with an expert within the Ethiopian Ministry of Science and Technology, providing funds and conducting supervision, and ensuring proper completion should not be the end of the process. In order to bring meaningful impact, proper dissemination and promotion of the research results should be done. 


\subsubsection{The International Livestock Research Institute (ILRI) ${ }^{21}$}

The International Livestock Research Institute (ILRI) is a non-for-profit international nongovernmental organization. Basing its headquarters in Nairobi, Kenya, it has a principal campus in Addis Ababa, Ethiopia. The organization's main goal is to alleviate poverty by improving the livelihood of farmers in developing countries, through the application of cutting-edge research results that arise out of its research activities.

ILRI has forged partnerships with several international donors. The organization works to improve the livelihood of farmers and to reduce poverty and hunger through effective knowledge-to-action activities and mainly by conducting scientific research that can add value to the stakeholders, primarily the farming and nomadic communities. The organization envisions using livestock to reduce poverty. It also provides scientific information and knowledge that is valuable to policy makers.

In general, LRI has a well organized library that provides excellent information services to researchers within and outside the institution. Housing current print and full-text electronic databases and journals and publications, the InfoCentre provides reference and information support services. The centre has books, full-text journals on CDROMs, online-databases, microfiches, videotapes, journals, theses, conference proceedings, maps, photographs, and newspapers.

\subsubsection{Ethiopian Development Research Institute (EDRI) ${ }^{22}$}

The Ethiopian Development Research Institute (EDRI) is a governmental research organization established in 1999 to conduct research on Ethiopian economic development in areas such as macroeconomics, agriculture and rural development, industrial growth, international economics, and human resources.

According to the organization's website, the primary goals and objectives of EDRI are:

- To conduct and promote high quality \& objective policy research,

\footnotetext{
${ }^{21}$ http://www.ilri.org/ (retrieved February 26, 2009)

${ }^{22}$ http://www.edri.org.et/
} 
- To disseminate the results of policy research,

- To build professional excellence and capacity in socio-economic policy analysis,

- To develop a policy research responsive to the needs of policy makers which is rooted in rigorous analysis,

- To create a research agenda that examines both short, medium and long term issues, and

- To serve as an effective forum for discussing development issues among key stakeholders.

EDRI holds conferences, seminars, workshops and has print publications to disseminate its research findings. A very few number of EDRI publications have summaries online. But in general EDRI does not use online mechanisms to disseminate its research outputs. ${ }^{23}$

EDRI has a website (http://www.edri.org.et/) but it does not seem to be well-managed, as the pages were last updated in 2005. There are no links to either the full-texts or abstracts of EDRI research publications. The website is in general poorly designed and not maintained properly.

\subsection{Access to Electronic Resources (E-Journals)}

This section discusses how the institutions and researchers therein have access to electronic resources that might be of value to their academic and research endeavor. The focus was to find out the extent to which e-journals are subscribed to and accessed by AAU, EDRI, and ILRI.

The Government of Ethiopia funds public universities and research institutes for the subscription and/or purchase of books and journals. This budget is, however, very limited and, hence, does not allow the concerned entities to subscribe to international journals. Most of the interviewees reported that their respective institutions did not subscribe to peer-reviewed journals.

The respondents mentioned that over the last few years their respective organizations have been involved in initiatives and projects that aim to provide better access to electronic resources. Many of the interviewees are aware of the INASP/PERI project. Some also

${ }^{23}$ http://www.gdnet.org/cms.php?id=organization_details\&organization id $=2438$ 
mentioned the HINARI and AGORA projects, which provide access to health and agriculture journals respectively. These three initiatives are prominently mentioned in articles that discuss about access to e-journals in developing countries (Arunachalam, 2003; Costa and Chan, 2005; Nwagwu and Ahmed, 2009).

In general some Ethiopian universities and research institutions currently participate in these three initiatives, namely, INASP/PERI, HINARI and AGORA. AAU is the national coordinating institution for these initiatives, facilitating the registration of institutions that want to have a negotiated and free access to electronic journals and databases. For example, AAU's Medical Faculty obtains funding for access to e-resources comes from two sources: the first comes from the University's own budget, and another comes from a grant from SIDA/SAREC. AAU in turn uses this grant to pay for subscriptions to electronic journals, not only for its own libraries but also for libraries found throughout the whole of the country. In fact, the University pays only $2-3 \%$ of the total costs of journals, as the prices are substantially reduced with negotiation from INASP.

Some of the electronic databases that are available to Ethiopian libraries and research institutions through the INASP/PERI project are Ebsco Host, Blackwell Synergy, AJOL, Cochrane Library, Cambridge University Journals, JSTOR, and Emerald Insight. However, AAU librarians reported that the usage of the INASP/PERI journals is very low. Low bandwidth, lack of awareness by university researchers and students, and information literacy problems have been highlighted as the major causes for the low usage rate of these electronic databases and journals.

One interviewee reported that the AAU's Medical Faculty has access to HINARI. Staff and students are given trainings on a regular basis in how to access HINARI journals. Access is based on username and password. As a result of the use of HINARI, resources such as PubMed Central, BMJ and other free access journals are available. AAU's Medical Faculty Library has, relatively speaking, the best resources when compared to other medical libraries in the country, such as Gondar University, Mekelle University and Jimma University.

ILRI gets its funds from more than 60 private, public and government organizations of the North and South. According to the information obtained from the interviewee from the 
Institute, the later distributes these funds to its research programs, including its InfoCentre, to purchase electronic and print information resources. In some cases, research departments themselves allocate funds and subscribe to and/or purchase books and other resources which are pertinent to their research. ILRI has a collection of more than 100,000 items, as print and/or electronic information sources. The institute also has access to AGORA. In addition, the InfoCentre provides access to free electronic journals.

EDRI has a special research library that houses books, conference proceedings, magazines, journals, and newspapers. Respondents from the organization reported that the Institute does not yet have subscriptions to electronic journals. But AGORA is freely available and the staffs make heavy utilization of free and open access journals. EDRI has also access to the PERI databases and staff can get passwords from the librarian that allows them to access the journals found in there.

When it comes to the question of access to electronic sources by individual researchers, what emerges is not encouraging. One respondent reported that he does not use scholarly journal articles through databases and e-journals. His access is limited to those electronic resources which are freely available through Google. However, in his studies abroad, he had access to a substantial number of online databases. "As a student", he says, "I had the right to ask for any article and the university library tried it best to get it, even if they the library did not have subscription to the item in question”. On a similar note, another $\mathrm{PhD}$ researcher attested that she used to have very good access to electronic journals while she was studying abroad. She further mentioned that accessing Ethiopian-related content is very difficult, as there are not enough journals and databases in the country. Another researcher also has had similar experiences and his perception of the situation is in complete agreement with the above two responses.

From these three responses, one can safely deduce that at least some Ethiopian researchers have very limited access to electronic resources, in particular scholarly articles. The initiatives by INASP/PERI, HINARI, and AGORA to provide access to scientific scholarly articles have not been matched by an adequate access level, mainly due to bandwidth problems while downloading articles. In addition, there seems to be a lack of awareness about the availability of these resources. It has also been mentioned that academic staff and 
researchers lack information literacy skills in the use such resources. Hence, this mismatch has slowed down the use of electronic journals.

One librarian noted that there are ongoing efforts in the newly established Ethiopian University and Research Libraries Consortium to integrate efforts in order to facilitate the access to e-journals. The librarian said that:

"As you know Ethiopian academic libraries are not strong. To coordinate efforts and resources and to develop an exit strategy from some of the projects as they will phaseout soon, we have now formed the Ethiopian University and Research Libraries Consortium. We held several meetings and shared responsibilities among the representatives from each organization and we are working towards registering it as an NGO in the Ethiopian Ministry of Justice."

The establishment of the consortium is believed to help Ethiopian libraries to share resources and avoid duplication of efforts.

\subsection{Dissemination of Ethiopian Research Output}

Respondents from AAU and EDRI reported that none of the Ethiopian journals and publications they have knowledge of are available online. Many agreed that researchers must go to a library in order to find out what has been done on a specific topic, and in many cases even the libraries do not have a list of research findings. One respondent, in particular, underscored the point that there exists a big gap between the knowledge community and policy makers in Ethiopia. There seems to be a lack of synergy between researchers and policy makers, as the later cannot easily access research outputs done in the country. This respondent identified the following two causes for this dilemma. First of all academic and research institutions that undertake research fail to properly promote and market their research findings and secondly, policy makers, leaders of industry and the public do not know what research efforts have been undertaken. "This," he says "is like a river flowing in its course without benefiting the people who have settled around it". The interviewee said the solution to the above two problems is to select research outputs that are considered to be beneficial to others and put them on the Web. For him, institutions have the responsibility and the mandate to fulfill this.

One respondent compared her access to electronic journals in Europe and in Ethiopia as follows:

"My university [in Europe] had many subscriptions to articles and journals. Therefore I had plenty of access to virtually any article that I needed. However, problems arose 
when it came to having access to locally-produced (i.e. Ethiopian) articles. Such items have not been published internationally, nor can you find them on the Internet. So, one would have to be present and request hard copies that might need translation or other modifications. This does not mean that there is a shortage of research articles. In fact, many articles have been written over the years. But the fact remains that these articles have not been published has created the impression that there is, indeed, a shortage of articles”.

AAU's Law Faculty can be taken as a typical example of a print-based and limited circulation of its publications. As mentioned above, the Faculty currently publishes the Ethiopian Journal of Law and four other thematic publications. The history of the journal goes as far back as the establishment of the Faculty itself. Published twice a year, it has for long been the only law journal in the country. Access to the journal and other publications is subscription-based, although they are available for purchase in Mega Book Store and AAU's Book Center. Neither the journal nor the other publications have an online presence. In fact, at the time of this study, the Faculty itself did not have a website.

The respondent from the Faculty has mentioned that the size of the legal community in the country had been very low in the past, but that it is currently growing rapidly, with the opening of new law schools. Accordingly to him, the circulation of the journal currently is about one thousand copies per issue. He believes that the circulation of journals and other publications will increase soon.

There are more than 5 law faculties throughout Ethiopia at present. In addition, there are law and human rights research and advocacy institutions and projects operating in the country. There also exist thousands of legal professionals, working as judges, prosecutors, consultants, and teachers. One wonders whether a single law journal, with a circulation of just around 1000 copies, is enough to satisfy all these needs.

It is worth mentioning the fact that one of interviewees seemed to be completely unaware of the existence of the Faculty's publications and said

"I did not know that AAU has such publications. They must have started publishing recently". When informed about the longevity of these publications, the same respondent highlighted the need to re-think about the dissemination of these and similar publications. 
Another respondent also pointed out the fact that the Faculty's publications were not visible to the international audience. Since there aren't any online dissemination methods for them, they are not easily accessible outside the country. Only a very few foreign libraries get hard copies. Hence, recent studies on Ethiopian legal issues, appearing in either the journal or the other publications, are not available for external researchers.

Another respondent highlighted the importance of producing electronic copies of legal research materials and making them available on the Internet, so that law students in the regional universities, legal professional everywhere in the country and individual researchers abroad who want to work on Ethiopian law could have easy access. This respondent went on to say that putting legal research online "could benefit a wide range of beneficiaries, mainly students and other universities (especially newly established ones). But this is hardly the reality here. Not many are able to purchase and put these materials into use, as there is the issue of transportation difficulties on top of monetary worries”.

Current attempts to digitize the Ethiopia laws are not well integrated. These are only separate and individual efforts and the resources are very scattered too thinly. Hence, a comprehensive and complete database for archiving the Ethiopian legislative literature and pertinent researches undertaken in the country is essential. The respondent also believes that a national database that would contain all published items is a necessity.

The same respondent furthermore argues that Ethiopia has a very poor road infrastructure. Hence, it is difficult to circulate print copies from one region to another, especially to remote places. The challenge could be addressed by developing the necessary Internet infrastructure, digitizing publications and putting them on the Web. Another interviewee said:

"I myself had to come to Ethiopian from [Europe] to collect research findings related to my $\mathrm{PhD}$ thesis. These unnecessary travels could have been avoided, had these research outputs been organized and put on in open access repository of some kind. Significant efforts have to be exerted in this respect”.

Some of the interviewees do not even have access to their own research results. They lost hold of their own work due to computer viruses, computer crash and other reasons. One interviewee in particular noted that: 
“to be honest, I do not have a copy of my Bachelor's degree thesis. I do not have copies of the researches I did while teaching at Mekele University. The only opportunity for you to have your research known to the general public is if you want to compete in research competitions, beside the requirement to present it to the finance office. Other than that, all you have to do upon completing a research is to file a report that claims that you have, and audit your finances for the research project.”

The findings of this study show that the dissemination outlet for Ethiopian research is mainly print publications and conferences. Many of the publications have limited circulation.

\subsection{Awareness to Open Access in Ethiopia}

Awareness about open access is very low among Ethiopian academicians, researchers and librarians. Many of them could not distinguish between free \& open source software and open access. According to the discussions, conducted during interviews, held with academic staffs, researchers and librarians of the various institutions involved in this study, open access has not made any significant stride in Ethiopia.

Relatively speaking, however, librarians are better informed about open access initiatives than academics. This better awareness by them is the result of participation in a single halfday workshop, held on December 22, 2008. The workshop, entitled "Open Access: How to improve accessibility, visibility and impact of your research outputs for librarians and researchers”, was jointly organized by eIFL.net and AAU. ${ }^{24}$

However, there were a few, even among the librarians, who had never heard of open access During the interviews with those librarians that had not participated in the previously mentioned Open Access workshop, they associated the concept of open access with free and open source software. Once open access is defined or described to them, many start explaining similar phrases such as free access, access to e-journals, various initiatives such as INASP/PERI, HINARI, and AGORA, etc. When asked about his awareness about open access, one librarian responded that he worked in the implementation of free and open source software for library automation. Only those respondents who attended the open access

\footnotetext{
${ }^{24}$ http://www.eifl.net/cps/sections/services/eifl-oa/oa-news/2009_01_11_open-access-workshop-in
} 
workshop mentioned previously could tell the difference between open access and free and open source software.

As some of the respondents are currently conducting research while abroad, they stated that they had heard about open access in their respective places of study, most of which were European universities. Though they have not yet published in open access channels, they have made use of institutional repositories and open access journals.

From the above, it is safe to assume that, open access it not yet well known in Ethiopia, even by librarians. This is especially true for researchers, who seem to have never heard anything about the subject. Researchers on the other do not link open access to FOSS. They try contextualizing the phrase to free-access. They make this informed guess and link it to access to e-journals. This is due to the fact that they had been informed about e-journals by librarians.

\subsection{Institutional repositories}

None of the organizations involved in this study have institutional repositories and institutional policies to mandate depositing or self-archiving. Most of them, especially government organizations, do not have properly designed and well-maintained websites that give access to current or past research outputs. In the course of a few years, even AAU, has changed its website from one interface to another. Furthermore, the present website lacks consistency as well as up-to-date of content and does not have links to many of its faculties, institutes and programs. To compound the matter, only Masters-level students and $\mathrm{PhD}$ candidates are required to submit a final copy of their theses and dissertations to the library through the university's Office of the Post-Graduate Studies. It is encouraging to notice that, very recently, in January 2009, the university has started running the Electronic These and Dissertations (AAU-ETD) on D-space.

Most interviewees reported that their institutions do not have a well established scholarly communication system that would address the actual and potential needs of stakeholders. An exception to this is ILRI. Ondari-Okemwa (2006) reported that "publications of ILRI researchers are well recorded and reported in the annual reports, as part of the knowledge management activities of the Institute”. ILRI provides links to PDF version of selected research articles on its website. Except for the ETD at AAU, all of the other research institutes of AAU and EDRI do not put full-text versions of research outputs on their 
websites. It is worth noting that ILRI has an easily navigable and searchable website and that the information is updated regularly. Even though the home page of AAU is well-designed, those of other research institutes, such as IES, IDR and IER, are not up to standard, let alone being state-of-the-art.

There were cases whereby some interviewees reported that they could not possibly see what other research institutes of AAU had done or are currently engaged in, as there is not any easily accessible database of completed or in-progress research

In the course of discussions held with the interviewees, it has been revealed that the root causes of the problem associated with the non-existence of a website or having a poorlydesigned and badly-maintained one is neither technical nor economical. Both AAU and EDRI have qualified ICT staffs who are versatile with advanced web technologies. Both have cutting-edge servers and other network infrastructure. One respondent mentioned that, AAU's lack of action in transforming its scholarly communication systems has been mainly cultural. According to this interviewee, the research dissemination culture of the university seems to be very poor. This seems to be borne out by the report of BPR Task Force which had, as already noted above, found out that the University lacks clear research policy and strategies, has no incentive mechanism for researchers, suffers from a shortage of research funds, a deficiency in effective \& efficient coordination, and an absence of keeping record with regard to what has been done in the various research projects (AAU, 2008).

\subsubsection{Institutional Repository Challenges}

As colloquially stated by Harnad (2006), Zeno's Paralysis, the paranoia and ungrounded fear of the researchers to self-archive their content in open access institutional repositories, has slowed the path to open access. Ethiopian researchers are not exempt from this paralysis. The problems are deeply interwoven with the poor research culture and dissemination outlets of public universities and research institutions. Compounding this problem is the blame game (transferring responsibilities to others) that has been observed being played by all concerned.

All interviewees are in complete agreement that Ethiopians should have the right to freely access publicly funded research in universities and research institutions including the ones they themselves have investigated. But when it comes to who should be taking such initiatives as advocates for free and open access, the researchers think that is the librarians' 
duty. When librarians were asked about their opinion regarding the matter, they respond that while the university management is willing to support the endeavour, there are staff members who still having misgivings about this, particularly in relation to copyright protection.

One AAU researcher expressed his concern regarding the possibility of plagiarism whenever he thinks of putting his work online. Another researcher, from EDRI, was of the opinion that sharing research data with researchers outside his own institution would be unthinkable. Furthermore, he also believes that government policy makers should precedence in having a first look at research findings, in some cases before it is public. .Librarians seem to push for deposit (archiving) mandates. Many researchers are hesitant on the subject, wondering whether this is indeed necessary.

Most if not all of the fears listed by (Harnad, 2006, pp.79-84) exist in many of AAU's faculties and research institutes. This seems to be the case at EDRI too. Librarians however appeared to be more willing to embrace open access than researchers. Most of them think that it is their responsibility to set up online systems for researchers. Especially ILRI staffs are very enthusiastic about open access

One librarian mentioned that ILRI staff who publish their works in peer-reviewed journals are not required to inform the InfoCentre (part of the library). Librarians have to therefore find out about such events by themselves in order to accomplish their mandate of keeping metadata of all articles that have appeared in peer-reviewed journals.

However, as can be seen from the AAU's ETD website ${ }^{25}$, the Faculty of Law, Institute of Ethiopian Studies, and the Institute of Educational Research have not added even a single collection to the repository. Even though this could be attributed to a number of reasons, one wonders whether a lack of initiative, action and commitment from staff of the concerned bodies could be included among these. Whatever the causes, they need to be rectified urgently. The AAU Library System is to be congratulated for taking up the initiative and managing to setup and maintain an institutional repository with the most cutting edge

${ }^{25}$ Addis Ababa University Library System (http://etd.aau.edu.et/dspace) 
software (Dspace). It will now be the responsibility of the University’s faculties, institutes, departments and researchers to take a keen interest in \& devise a proactive approach in using the opportunity to archive/deposit their research findings and make their outputs visible thereby maximizing access. The fact that the Faculty of Science is taking the lead, by archiving 536 theses and dissertations, is encouraging. This is an initiative worth emulating.

MoST currently does not have any electronic database for the purpose of depositing research results. This is also true for EDRI. ILRI, on the other hand, maintains a Publications Database but this does not satisfy the Open Archives Initiative Protocol for Metadata Harvesting (OAI-PMH) requirements of, in order to be harvested by major harvesters and repository directories.

\subsubsection{Electronic Theses and Dissertations in AAU}

Theses and dissertations constitute a big share of African universities' research outputs. Students exert resources and intellectual effort to produce hundreds of pages of empirical research while supervisors and examiners ensure that the proper research methodology and data analysis techniques are followed in order to ensure that the appropriate level of quality and integrity is maintained.

Nonetheless, these research results are not organized, properly managed and maintained in libraries. Availability is limited within the walls of one or two libraries. The print bound copies easily get damaged or get lost.

African researchers have suffered from a lack of access to an African content. Cognizant of the prevailing access problems in Africa, the Database of African Theses and Dissertations (DATAD) project was initiated by the Association of African Universities to create mutual understanding and cooperation among African universities to develop an organized collection of electronic theses and dissertations thereby improving access and increase the visibility of African scholars (Ubogu, 2003).

Ubogu (2003) acknowledged that some African universities, mainly in South Africa and Egypt, have shown progress in digitizing theses and dissertations. In the beginning most of these ETDs had only bibliographic information but slowly they moved on to full-text.

When a three-year pilot project, involving 11 institutions, was initiated in 2000, Addis Ababa University (AAU) was one of the active members of that initiative (Ubogu, 2003). As per the 
discussions held with librarians of AAU, several conferences had been organized at AAU and participants drawn from other regional universities had participated in these conferences. Since the initial purpose was to provide online bibliographic database, the AAU library started the project and data entry was began. But changes were not visible. While similar projects, including the one at the University of Witwatersrand, managed to get their ETDs up and running, AAU had not shown any progress. The librarians at AAU attributed this laggardness to the lack of copyright policy, weak management support, poor ICT infrastructure and the shortage of qualified technical staffs. According to one librarian, some of these problems have now been solved. One of the positive changes mentioned is related to management support. The University's Research and Post-Graduate Studies Office and all other concerned bodies are now committed to work with the library to overcome these wide ranges of problems.

All of the librarians interviewed agreed that AAU's Library has to take bolder initiatives, not only in re-starting what has been planned in the DATAD project in 2000 but also in going beyond theses and dissertations so as to include other major research outputs and publications produced within the University.

Based on the interviewees' responses, what can be said in hindsight is that AAU failed to actively engage itself to implement what was sought on the DATAD initiative. While the initiative demanded universities to establish working teams consisting of librarians, the University's management, ICT staff and other stakeholders, AAU failed to constitute such a team. Consequently, the DATAD project failed to take off the ground and achieve its goals in AAU. However, the DATAD project helped AAU's Library bring awareness about the potential benefits of ETD and led to the development of the current ETD on D-space.

According to AAU's librarians, the library is now fully committed to running and maintaining the AAU-ETD on Dspace system. Public IP address for the new system has been acquired and technical capacity to administer the system, update new plug-ins, and debug problems has been put in place. Three of the four librarians interviewed are actively involved with the new system, both from a technical as well as a managerial point of view. Of course, there is a lack of content in the AAU-ETD undertaking, but these librarians believe that there has been quite a significant amount of progress and that the addition of content to the system would improve, albeit slowly. 


\subsection{Mandating Self-archiving}

Regarding the question as to whether researchers would be willing to permit that their research outputs be put on an open access repository, one respondent perceives the problem from two perspectives:

1. There is an assumed reluctance from the side of researchers, as that being on open access implies that their outputs will be seen by everyone and some might be afraid of its quality being below standard. Hence these researchers may not let the work be visible to the wide world.

2. On the other hand, tax payers should have the right to access research outputs that have been undertaken using money contributed by them.

The second perspective is upheld by another interviewee. According to him:

"The public has the right to demand access to such research outputs. Because, in one way or another, many research undertakings are done using public funds. Even if one excludes direct public funding, researchers use public infrastructure such as the Internet and office supplies to conduct their research. Hence the public should have the right to claim access to such research freely and openly”.

Another interviewee reported that there might be possible resistances from some researchers who fear that opening access would infringe upon their copyright and patent protection rights, as well as exposing their work to plagiarism. This interviewee believes that librarians need to respond to such questions with the appropriate answers, as well as assuring researchers that putting their findings online would benefit them in many ways. This, the interviewee, believes, needs quite a lot of discussions and awareness creation effort by the librarians themselves.

None of the organizations studied require researchers to deposit their final research e-prints. Some of the major reasons for this state of affairs could be a lack of institutional repository systems, absence of institutional policies and mandates, and lack of willingness to take such initiatives, both from the side of the libraries and university management and including the researchers themselves. AAU has made it a requirement for its postgraduate students to provide final electronic version of theses and dissertations. This has to be made the practice 
in the remaining institutions. Many respondents believe that funding institutions such as the MoST should mandate the storage of research outputs in a central open access repository.

\subsection{Open Access and Its Potential Benefits to Ethiopia}

Most of the respondents reported that opening access to Ethiopian research would benefit the researchers, their institutions and the public at large. One researcher reported that:

"This is what I believe. When you publish or put work available to be accessible by many people, in one way you are letting yourself out for criticism. For example, if I do a research on a legal issue and present it to a conference where the participants are water engineers, they do not have the depth know how of legal issues to criticize my work. But if I publish this research in an open online system, it is much likely that many lawyers are going to read it hence I would receive constructive comments on my work. This then may boost my academic reputation. So this is very useful.”

In the course of the various discussions, held as part of the interviews conducted, it was found out that respondents are enthusiastic about embracing it and many of them believe that open access would allow Ethiopian researchers to participate in the scientific debates and contributions around the globe. In answering the question as to how open access would benefit Ethiopia, a respondent emphatically said that:

"Well, open access is a new concept; I believe it brings lot of benefits for developing countries like Ethiopia and even for the whole continent. Those materials and research results that can be accessed using password or those that are of hard copy and on the shelf have less impact since it is unreachable to most of those who need it”.

In addition, one respondent boldly indicated that open access could help Ethiopia in poverty reduction and economic growth. 


\subsection{Conclusion}

The institutions involved in this study such as AAU, EDRI, and ILRI are engaged in research efforts that are aimed at alleviating poverty, by fostering social and economic development through effective utilization of research-based knowledge. By and large, these institutions have developed different outlets of research dissemination mechanisms. Among these are conference proceedings, publications, journals, research reports and databases. Except for ILRI, other institutions relied mostly on print publications for disseminating their research outputs. They do not seem to keep electronic copies of their publications and most of their journals are not indexed.

The access to e-journals is limited. There is shortage of bandwidth to download journal articles that are offered through international projects such as INASP/PERI project. Open access has not been implemented in the country and there is little awareness about it.

According to the findings of this study, AAU lacks clear institutional policies and strategies to disseminate the results of its research activities. Both AAU and EDRI do not yet have any institutional storage/repository system for their research outputs. Consequently, their researchers' visibility, both domestically and internationally is very low. Researchers, students, industry leaders and the general public do not seem to have adequate access to most of the research findings that has been conducted within these two institutions.

Currently there exist multi-faceted problems of bandwidth, lack of awareness, poor institutional research infrastructure, poorly managed websites, and absence of institutional policies for depositing research results. These challenges call for change in the way the Ethiopian scholarly communication system operates. 


\section{CHAPTER FIVE}

\section{CONCLUSIONS AND RECOMMENDATIONS}

Based on the interviews, observation and reviewed literature, this chapter provides conclusions and recommendations about the existing system of the Ethiopian scholarly communication system.

\subsection{The Need to Change the Status Quo: Towards an Open Access Scholarly Communication Model for Ethiopia}

In the $21^{\text {st }}$ century, where knowledge has been considered as the competitive edge for excelling in what organizations envision, research and development is a crucial endeavour. Universities and research institutions are knowledge-based social entities where knowledge is generated, developed, adapted and disseminated. Government policy makers, industry leaders and the general public benefit from the continuum of knowledge creation through scientific research. Knowledge is shared through conferences, journals, institutional archives and other forms of scholarly communication.

Currently, what seems to be the common practice in the institutions involved in this study is writing proposals, obtaining grants, conducting research, preparing reports and sending copies to donors (the finance office, if it is within AAU for example). Then both the investigators of the research and donors lock that research in their shelves. This is typically the case for the MoST, which has a funding scheme that is known as Local Research Grant (LRG). Researchers from all over the universities and research institutions apply for this grant. MoST does not have a system to organize and disseminate the research results that emanate from the grant. Only EDRI and some of the research institutes of AAU disseminate their print publications to selected institutions within Ethiopia and very few of them publish journals.

The current scholarly communication model in Ethiopia cannot and will not be able to address the needs of the country. The Government has embarked on a massive expansion of public universities and the number of student intakes is increasing year by year. Postgraduate education (both at the Masters and PhD levels) is on the rise, industries are booming, research 
institutions are being instituted and their number is growing steadily and yet the scholarly communication outlets are very limited and out of date. Many students who are studying abroad and researchers across the world may need to access research work that has been investigated in Ethiopia and yet there are no institutional repositories, electronic journals, and properly designed websites to provide such services.

These daunting problems cannot be addressed by an evolutionary transformation of the Ethiopian scholarly communication model, but call for a revolutionary approach. Embracing open access models could help achieve such a complete revamp of the current print-based and limited distribution model.

Institutions such as AAU should overhaul their research dissemination system. They need to recognize that Ethiopian research is hardly visible, not only to people elsewhere in the world but even to Ethiopian policy makers, scholars, students and industry leaders. As pointed out by Swan (2007) developing countries are hard-hit by the subscription-based scholarly communication model, as researchers in these countries cannot simply afford to pay for access. While open access has become a talking point for many researchers and librarians in the developed world and has been embraced by wealthy institutions when they recognized that they could not afford to subscribe to the ever increasing number of journals, developing countries are slow in up-taking such initiatives. It is therefore essential for countries like Ethiopia to design open access strategies that is contextualized to the needs of researchers and the demands of other stakeholders.

\subsection{Ethiopia is still Printing}

Many countries are moving from the print to the digital media, especially in scholarly communication systems; existing print journals are converting their publication models to digital and many journals are becoming digitally borne?. The running cost for the print and digital version of journals is incomparable. Most journals are published online and the dissemination is made through the Web, which reduces the cost considerably.

Journal publishing by universities, professional associations, and research institutions in Ethiopia is very low. The Ethiopian scholarly communication system is mainly print-based. The price of paper and printing is increasing steeply. It can be argued that it is still essential 
to print research publication on paper, as the digital divide exists between those institutions which are located in big cities and those who are in remote places where there is no access to the Internet. However, the universities and research institutions need to make their research visible to the entire world so that Ethiopian researchers are able to participate in the global scholarly communication system of knowledge sharing and collaboration.

The Government of Ethiopia is improving its telecommunication infrastructure. The SchoolNet and WoredaNet projects are connecting rural schools and administrative councils through fibre optics technologies. These are big investments to a country where resources are so meagre. Universities and research institutions should take advantage of this infrastructural development to channel content to these and other networks so that they can reach out local stakeholders including other universities, researchers, the public and industry leaders. Without ICT infrastructure (both access to computers and Internet), open access cannot succeed. The Ethiopian Telecommunication Corporation should provide adequate bandwidth for universities and research institutions.

\subsection{The Need for Concerted Effort}

It is apparent that in order for open access initiatives to succeed it should get government support. In order to implement open access and promote open access, the Ethiopian government through its Ministry of Science and Technology should develop a policy in consultation with universities, research institutions, libraries, funding agencies, and renowned researchers. The Ethiopian Ministry of Science and Technology (MoST) should coordinate the draft the adoption of an open access policy. Lessons can be learned from South Africa and other countries who have successfully implement open access. The following recommendations are based on what Peter Suber suggested countries should do to promote and implement open access (Suber, 2007) ${ }^{26}$.

- The Ethiopia government should put a condition on government research grants that anyone who accepts a research grant should agree to provide an open access to the research results(reports);

- Permit recipients of government research grants to use grant funds to pay the processing fees charged by OA journals: when research grants are offered to

${ }^{26}$ http://www.earlham.edu/ peters/fos/do.htm 
researchers, the grant should include money for publication of the research results in author-pays open access journals so that anyone can access and use it freely and openly;

- Annual government budgets for Ethiopian universities and research institutions should include budget lines for setting up institutional repositories so that hardware, software, training and maintenance costs can be covered;

- Ethiopian research and cultural heritage is not yet digitized. Government should therefore initiate national digitization projects. The Ethiopia Information and Communication Technology Development Agency (EICTDA) should take the responsibility of such digitization initiatives. The agency should work with libraries and ICT centers of universities and research institutions so that the agency would oversee digitization projects, support such effort with government funding, help in providing digitization standards and help avoid duplication of digitization efforts;

- Ethiopian universities and research institutions should include in their contract for employment that any research work conducted by salaried staff members should make it open access;

- The Ethiopian Ministry of Science and technology in collaboration with universities, research institutions and other responsible government bodies should work to develop a national open access repository of research. Such online service should be able to harvest those repositories which are located elsewhere in the country and provide a single search interface to browse and search for content from those repositories.

- The Ministry of Science and Technology should mandate the deposit of a copy of the research conducted through its Local Research Grant (LRG) to institutional archives of the researchers. The ministry should also develop a national science and technology repository which can be accessible freely to everyone through an open access license;

- The Ethiopian Ministry of Science and Technology should sign the Berlin declaration so that public funded research becomes open access and Ethiopia abides by such international statements of action. This will help invigorate national open access efforts. Signing such declarations will also help to coordinate efforts at a regional and international level. 


\subsection{Awareness about Open Access is Crucial}

Both the academic and library staffs seem to be deficient in their awareness about open access. The only effort to address this deficiency seems to be the one started by eIFL.net, which took the first initiative to create awareness about open access in a half-day workshop. Unfortunately, the participants have not held similar workshop events or put in place link on their websites to inform researchers, students and librarians about the role of open access in scholarly communication

Ethiopian universities and research institutions should have open access advocates, selected both form the research community and librarians, who would organize short events to create awareness by addressing such issues as "What is OA? Why is OA important? What is selfarchiving? What are institutional repositories? How can researchers participate in the global OA movement by contributing their own research articles? What are OA journals? What Free and Open Source Software exist to set up institutional repositories and OA journals?”

This awareness creation exercise could also be expanded with the use of institutional websites, brochures, notice boards and local staff meetings. Participating students in such events could help spread the message as they reach many audiences. Celebrating the Open Access Week, declared internationally by open access proponent institutions from October 19 $-23{ }^{27}$ would also be useful in bringing attention about the OA. The Dutch higher education sector, for example, has declared 2009 to be 'Open Access Year'. ${ }^{28}$

\subsection{Institutional Repositories: Ethiopia’s Green Road to Open Access}

AAU should widen the scope of its ETD in to an institutional repository hence the other types of research works would be archived and made accessible anyone interested in the works. This would maximize visibility of AAU researchers and that would in turn increase research impact. ILRI should ensure whether the current software and metadata standards they are used by the databases are interoperable with international standards.

\footnotetext{
27 http://www.arl.org/sparc/media/09-0305.shtml

28 http://www.surffoundation.nl/smartsite.dws?ch=ENG\&id=5378
} 
The BPR Task Force's recommendations have not yet been implemented at AAU. One would have liked to hope that these recommendations, when implemented, would overhaul the whole research process and dissemination strategies. Unfortunately, the BPR report has not given much attention to research dissemination. The University's BPR should include a detailed strategy of re-engineering the process of research dissemination at AAU. The overhaul should also include mandating self-archiving of research results of all research projects within the university, theses, dissertations, and also developing institutional repositories.

EDRI disseminates its research results through thematic publications and distributes them to selected institutions within Ethiopia. The circulation, however, is very limited. The organization should re-design and update its website. EDRI should also develop an institutional repository and make its digital copies of its publications accessible to the public and other potential users worldwide.

Many major universities and research institutions use their websites as major outlets to disseminate research, promote their activities and reach stakeholders including students. AAU's research institutes, the Ethiopian Development Research Institute and other Ethiopian universities and research institutions should not underestimate the power of well-designed and professional websites that are updated and maintained on a regular basis. The websites should be up and running 24/7. In this regard, ILRI's web portal is very accessible and easy to use. Ondari-Okemwa (2006, p.69) reported ILRI’s portal as:

“To enhance knowledge and information sharing, ILRI has developed and continues to build an information portal. Research scientists of all ILRI research centres have access to the portal and contribute to it. The portal is user-friendly and enables ILRI research scientists to exchange knowledge and information more easily with fellow research scientists in collaborating organizations”.

The AAU research institutes and EDRI need to learn from ILRI's successes in designing, running and maintaining a successful website that fosters collaboration among researchers. According to Ondari-Okemwa (2006), ILRI maintains a database of publications of its researchers and compiles it in its annual reports as part of its knowledge management 
activities of the Institute. In the absence of institutional repositories, researchers would have perhaps been encouraged to link their teaching materials and full text research results. These organizations, including MoST, should design and develop an OAI-PMH compatible institutional repository. In the case of MoST, this should be a national one.

\subsubsection{Mandating Self-archiving: the Prophylaxis against Zeno's Paralysis}

Harnad (2006) strongly argues that the Prophylaxis against Zeno's Paralysis is mandating self-archiving. Organizations should also take a carrot and stick approach to reward those who deposit or self-archive or to penalize those who fail to do so. According to Guedon (2006) mandating alone is not enough. In parallel, the institutions should devise incentive mechanisms for researchers who deposit their researches. These incentives should be in the form of intangible benefits such as promotion, prestige, and authority that also comes through the impact of making one's research visible.

So far none of the institutions including ILRI have institutional mandates for self-archiving. The experiences of many other countries and institutions show that mandating self-arching is an effective strategy (Guedon, 2006). Hence AAU, EDRI and ILRI should devise mechanisms to make it mandatory for researchers to deposit, especially publicly-funded research results, to an institutional repository designed for such purpose. MoST should mandate the deposition of a copy of the research conducted through its Local Research Grant (LRG) to institutional archives where the researchers are based. The Ministry should also develop a national science and technology repository that is freely accessible by whoever wants to do so through an open access license. In this regard, Suber (2009) recommends that “if you're serious about achieving OA for the research you fund, you must require it”.

What AAU libraries should do is creating more communities in D-space and liaising with University faculty deans and institute directors to encourage them to submit their research eprints, research reports, and theses and dissertations. The University Librarian, the Office of Post Graduate Studies, Deans and Directors should conduct a consultative meeting and institutionalise the mandating of submission of final research reports, theses and dissertations to the Dspace institutional repository.

It is worth noting that AAU's post graduate students, and some academic staffs currently do not have institutional email accounts. This makes it difficult for researchers and students to 
submit their e-prints/theses and dissertations remotely. It is also important to note that there is an information literacy problem. While both of these would be addressed in due time, to get things happen in the interim period, the situation demands a mediated submission by librarians.

\subsubsection{The Need for National and Institutional Open Access Policies}

We recommend that Ethiopian universities and research institutions should embrace open access as their model for scholarly communication. It is also recommend that they should mandate the submission and self-archiving of research results especially those theses and dissertations, research that has been done with public-funding. Public funding here refers those research projects funded by government funds such as the LRG of MoST. In fact open access can be embraced without national and institutional policies and strategies.

Hence, MoST as a national government body, should take the initiative of developing a national open access policy. It is felt that that putting in place such policies and procedures would allay some of the concerns expressed by researchers. Institutions such as AAU, EDRI and ILRI should also adopt institution-wide policies. Lessons can be learned from other developing countries and institutions which have adopted open access policies.

Suber (2009) ${ }^{29}$ suggests that funding organizations and universities should require, and not request, self-archiving. In many institutions in Ethiopia, there are no electronic repositories. Until such a mechanism is put in place, authors should be required to submit the last PDF version of their research results (theses, dissertation, pre-prints, post-prints, and reports) to their respective libraries. Libraries will therefore be required to develop digital repositories and make such works accessible to all.

\subsubsection{Use of Licenses in Institutional Repositories}

Authors and librarians need to about the Creative Commons (CC) and other alternative licenses to copyright. Librarians need to advise researcher on the use of CC licenses and continually consult SHERPA's RoMEO website to check the publisher's copyright \& archiving policies. Institutional repository managers in consultation with authors and university managers should customize the CC licenses to their interests and make sure that

\footnotetext{
29 Suber, P. (2009), "Open access policy options for funding agencies and universities", Welcome to the SPARC Open Access Newsletter, issue130 available at: http://www.earlham.edu/ peters/fos/newsletter/02-02-09.htm\#choicepoints (accessed 07 April 2009)
} 
the authors understand these licenses and submit their contents using such agreed upon licences.

In customizing CC licenses, Ethiopian universities and research institutions should ensure libre open access instead of gratis open access. While the first type of open access removes only price barriers, the second removes both price and permission barriers. In other words, the licenses should allow optimum flexibility in the use, adaption, and even commercial use of content. The license should ensure the works should be used with integrity and proper attribution.

\subsubsection{Free and Open Source Institutional Repository Software}

It is important to note that highly scalable, tried and tested software for institutional repository development is free and open source. One such software is Dspace which is being used at AAU. There are also other major ones such as E-print, CDS Invenio, and Fedora. Ethiopian universities and research institutions should use this opportunity. They need to develop technical capacity and form online software communities to support the customization, installation, configuration and maintenance of such systems. AAU may take such initiative to organize trainings to regional universities.

\subsubsection{Federation of Ethiopian Institutional Repositories}

Jones, Andrew and MacColl (2006) argue that setting up federating institutional repositories than a central one offers more scalability and the feeling of ownership by the institutional and also the scholars who provide content to the repositories. They recommend distributed and grid storage mechanisms.

The federated repository architecture offers the possibility for institutions to easily populate content and metadata, and set-up own institutional policies. The federated repository architecture would provide a sense of control in the management of research results and confidence in the institution's commitment of resources. However, in cases where the size of the institution is small and manages only few research results, the technological and staff time expenditure might not justify the expenditure hence a centralized repository might be the way to go.

Ethiopian universities both old and newly booming, research institutions both in the capital and in the regions should therefore work towards a federated digital repository where content 
can be harvested using OAI-PMH compliant architecture where standardized metadata such as Dublin Core is used. Such architecture offers the ability for users to search all systems as one.

\subsubsection{Institutional Repositories should be OAI-PMH Compatible}

Institutional or subject-based repositories should fulfil some basic minimum requirements. Jones, Andrew and MacColl (2006) specify that institutional repositories should use a software that is open and interoperable. The institutional repository needs to be interoperable with other repositories. To this end, it needs to be OAI-PMH compatible. The OAI-PMH protocol is a technical solution using HTTP, XML and Qualified Dublin Core and enables to harvest metadata and provide cross searching of repositories. Compliance to the OAI-PMH standard simply means the repositories of separate institutions can be harvested and searched. The standard requires using an accepted set of metadata schemes and elements such as the Dublin Core metadata element set. An analogy for this could be the union catalog of libraries except in the case of OAI-PMH based repositories; the full-text articles can be searched in addition to the metadata/catalog. The institutional repository systems need therefore be OAIPMH compliant in order they become searchable by search engines.

\subsection{Open Access Journals: The Golden Road towards Open Access To Ethiopian Knowledge}

Canessea and Zennaro (2008, p.25) wrote that open access journal publishing can help Africa to "close the knowledge gap between the well-funded and powerful voices from the North and often-overlooked ideas, innovations, and discoveries from the South”. There are very few print journals in Ethiopia. Their circulation is limited. Unless existing journals go online and new open access publishing initiatives take place, Ethiopia will continue to witness a knowledge divide that already existed in the country.

The only open access journal that Ethiopia offers freely to the world is the Ethiopian Journal of Health Development by the Department of Community Health, Addis Ababa University. Edited by Prof. Prof. Yemane Berhane, 3 associate editors, 10 editorial board members, and 24 editorial consultants, the journal is peer-reviewed and published three times a year. According to the journal's home page, the journal is "the main forum for exchange of information on public health in Ethiopia, and has been in print since 1984. The Journal is 
useful for policy makers, managers, practitioners, researchers and students”. ${ }^{30}$ The online version is currently hosted in the University of Begen in Norway. The print version of the journal is subscription-based and an annual subscription costs 60Birr (6USD) for local subscribers and 75USD for subscribers outside Ethiopia. The online version however is free for anyone to download and use PDF copies.

In choosing the golden road to open access what AAU, EDRI and ILRI should do is while continuing the print version in the way they are doing it currently, they should follow the example of the Ethiopian Journal of Health Development by putting the online version of the journals and publications on an open access system. It should be noted that the Ethiopian Journal of Health Development is an open access journal. It is however hosted in a server based in Norway. Our recommendation is that universities and research institutions should also own the server and host it locally so that administration and maintenance is easier.

In chapter two six categories of OA journal models are discussed. These are the author pays, subsidized, dual-mode, delayed, partial and per-capita models. It is noted that the author pays model is the dominant model. Ethiopian universities and research institutions should utilize these models based on their specific contexts. Addis Ababa University may use the dualmode model for the Journal of Ethiopian Studies, the Ethiopian Journal of Development Research (EJDR) and the Ethiopian Journal of Law. The hybrid model would allow AAU to continue the subscription-based print journals while allowing converting these journals to electronic forms and made them accessible as open access journals.

The journals should be converted into online journals with similar content of the print versions. Since the final e-prints are already produced electronically, it is does not require to digitize the print versions. In fact, there will always be a need to digitize the back issues of these journals.

As it has been discussed in chapter four, EDRI publishes thematic print publications to disseminate its research results to registered members of organizations within the country. ILRI disseminates both print and link electronic versions of some of the articles on its

\footnotetext{
${ }^{30}$ http://ejhd.uib.no/
} 
website. However it does not have an online journal to organize and systematically disseminate. ILRI and EDRI should set-up an online journal system using open source software such as the Online Journal Systems (OJS). OJS is "open source software made freely available to journals worldwide for the purpose of making open access publishing a viable option for more journals, as open access can increase a journal's readership as well as its contribution to the public good on a global scale”31. AJOL for example uses the OJS software(http://ajol.info/). A complete list of who uses OJL can be obtained from http://pkp.sfu.ca/ojs-journals. As can be seen OJS is reliable and easy to use open source software that can be easily customizable to the needs of Ethiopian universities and research institutions to publish online journals.

\subsection{Open Access to Data: the Way Forward}

Once Ethiopian research institutions implement institutional repositories, the way forward should be discussions about open access to data. Many institutions in the developed world are no instituting a policy and funding agencies are requiring the open accessibility of public funded research data. In 2004 the Organisation for Economic Co-operation and Development (OECD) countries science and technology misters convened and discussed on devising strategies for open access to data collected through public funding and in 2006 principles and guidelines were prepared and endorsed by member countries (OECD, 2007). This shows the issue of open access is not limited to peer-reviewed research hence Ethiopian institutions should work in concert towards open access to research data.

\subsection{Open Access is not Costless}

Information and communication technologies have played a transformative role in the process of data collection, analysis of results, report preparation, peer-review facilitation, and publication and finally the dissemination and use of research. With the use of the web for much of the process of scholarly communication, the reduction in cost has been felt and conceptualized and many librarians, researchers and funding agencies have started asking questioning the real cost of the publishing of scholarly articles. The fact that the intellectual product has been given away by its authors as royalty free and the ubiquity of Internet

\footnotetext{
${ }^{31}$ http://pkp.sfu.ca/?q=ojs
} 
publishing that dramatically reduced the marginal cost of publishing and distributing articles, there has been a call to re-evaluate the traditional scholarly communication model which has been very slow to accommodate to the needs of researchers and librarians. That served as an impetus for the development of the open access initiatives.

However, open access itself is not costless. It involves personnel, hardware, software, communication, training and maintenance costs. Open access initiatives therefore require a viable plan and allocation of resources. There exist free and open source software to set up institutional repositories and open access journals. There are, however, hardware costs. Besides, installation, customization, and maintenance of institutional repositories and open access journals entails significant amount of resources. These costs therefore need to be acquired, allocated and used in order to provide sustainable open access services.

Hence, Ethiopian universities and research institutions should solicit and allocate financial resources that would cover the personnel, hardware, software and training costs of the open access initiatives. Funding agencies need to include publication costs as part of their research grants therefore authors would be able to publish on traditional journals which have adopted the 'author-pays' open access model.

\subsection{Practical Implications and Future Research}

This qualitative case study research does not need to be generalized for all contexts. The findings and recommendations can, however, be transferable to similar institutional contexts. It is hoped that the findings and recommendations of this research will help Ethiopian universities and research institutions to re-think their policies and strategies on scholarly communication systems.

This research by no means sought to find out the truth on scholarly communication models. It is however believed that the recommendations will serve as staging grounds for further exploration of the role of open access in Ethiopian research. 


\subsection{Conclusion}

Over the last ten years open access has been a hotly debated issue and quite recently has been taken up by educational institutions and implemented very widely especially in developed countries. Some developing countries have also stepped in to the bandwagon with institutional repository systems set-up and self-archiving policies adopted. Currently, more than 1,400 open access institutional repositories provide to hundreds of thousands of research articles and the number is growing even faster. The discussion about open access is still in its early stage. There are several technical, financial and social issues to be addressed.

The benefits of open access in streamlining the scholarly communication process by creating new channels of access and dissemination to research is substantial. Many governments at congressional/parliamentary levels instituted special committees to look at open access to public funded research. It is thus imperative for developing countries to give due attention to open access issues. Open access has a lot to offer especially for developing countries where academic institutions have e meagre to resources to access and disseminate research results.

Arguably, this is a time when we all profess about the effects of globalization that is fuelled by the web. Researchers in developed and fast growing nations are actively engaging themselves in generating, sharing and leveraging knowledge. Developing countries researchers and especially Ethiopian researchers seem to lag behind in harnessing ICT to disseminate and access research. Ethiopian research dissemination system is print-based and public universities and government research institutions have not embraced new initiatives such as open access. The author of this study has experiences that Ethiopian universities do a lot of research work though extremely low compared to developed countries. Nonetheless, the dissemination system is very low. Unfortunately, this problem waited for so long unaddressed.

Suber, Nair and Hussain (2009, p.1) argue that "research is incomplete until its results have been communicated". In short, while Ethiopian researchers have done thousands of researches on pressing issues, the logical argument given by Suber, Nair and Hussain leaves the significant part of Ethiopian research incomplete. And the reason is simple, it has not been communicated. Nielsen (2009) described the need for publishing as follows: "The great physicist Michael Faraday could advise a younger colleague to “Work. Finish. Publish”. The 
culture of science had changed so that a discovery not published in a scientific journal was not truly complete”.

The development of institutional repositories and online journal publishing systems is very low. Consequently, Ethiopian researchers remain invisible and their research results are locked in obscure library and office shelves. Apparently, Ethiopian research is hardly visible on major search engines and directories. As the existing print publications have limited circulation, Ethiopian authors do not get citation impact which directly affects their reputation, promotion and other benefits that they would have got had they been visible. The current scholarly communication system is faced with technological and social challenges and open access offers an opportunity to Ethiopia to transform the current moribund scholarly communication system in the country.

To increase visibility hence bring the required impact, institutional repositories need to be set-up. The repositories need to be populated with selected, peer-reviewed academically valuable content. Infrastructural problems such as computing and bandwidth needs should be addressed. Realizing this in the very near future is in fact easier said than done. It demands concerted effort of librarians, IT people, researchers, managers and funding agencies.

Ethiopia should embrace the opportunities presented through open access initiatives. Funding agencies, Universities and research institutions should take bold actions in adopting open access policies and strategies in a concerted fashion. Ethiopia should learn lessons from Southern African countries that have successfully lied down visions and strategies for an open access to knowledge.

Even though this seems to be a daunting task, it is worth noting that not only is it absolutely necessary, but that it can be made feasible. Ethiopian universities, research institutions and funding agencies should mandate self-archiving especially for research that has been carried out through public-funded money. What the open access proponents call the green-road to open access is the viable alternative to get Ethiopian researchers out on the web to contribute share their knowledge to other scientists across the globe and also to access what others have contributed. Open access journal publishing models should also be embraced with strategic viable plans that take into account the challenges of setting up and running journals. With the 
availability of open source journal management software, existing print journals of Addis Ababa University and publications of ILRI and EDRI should start OA journals.

Open access should be approached as a double edge sword: it improves access to research done elsewhere and enables researchers publish their works. Ethiopia should not miss this golden opportunity to leapfrog the knowledge divide that has persisted for so long. 


\section{References}

AAU (2008). Addis Ababa University Business Process Re-engineering Task Force Report. AAU BPR” http://www.aau.edu.et/AAUBPR\%20AS\%20IS/BPR-

AAU\%20Research\%20AS\%20IS\%20Report.pdf

African Union (2006). African Union Ministerial Conference on Communications \& Information Technology (CIT). Retrieved from http://www.uneca.org/disd/events/2006/arapke/resources.html (accessed 12 March 2009).

Ahmed, A. (2007). Open access towards bridging the digital divide - policies and strategies for developing countries, Information Technology for Development, 13 (4), 337- 361.

Arunachalam, S. (2003). Information for research in developing countries - information technology, a friend or foe?, International Information \& Library Review, 35(2), 133147.

Arunachalam, S. (2008). Open access to scientific knowledge. DESIDOC Journal of Library and Information Technology, 28 (1), 7-14.

Bailey Jr., C.W. (2006). What is open access. In N. Jacobs (Ed.), Open access: key strategic, technical, and economic aspects (p. 13-26).Oxford: Chandos Publishing.

Canessa, E. \& Zennaro, M. (Eds.) (2008). Science dissemination using Open Access: A compendium of selected literature on Open Access. Trieste: ICTP.

Canessa, E., Fonda, C., Zennaro, M. and Sreenivasan, K.R. (2006). Access to scholarly literature via a free knowledge management enabler: an opportunity for scientists in developing countries. Knowledge Management for Development Journal, 2 (3), 75-85. Retrieved from www.km4dev.org/journal (accessed 25 October 2008).

Chan, L. and Costa, S. (2005). Participation in the global knowledge commons: challenges and opportunities for research dissemination in developing countries. New Library World. 106(1210/1211), 141-163.

Chang, C. C. (2006). Business models for open access journals publishing. Online Information Review, 30 6, 699-713.

Cockerill, M. (2006). Business models in open access, In N. Jacobs (Ed.), Open access: key strategic, technical, and economic aspects (p. 111-119).Oxford: Chandos Publishing.

Cockerill, M. (2007). Pricing, business models and open access: Status quo vs. Apocalypse, IOS Press, 27(40), 235-238.

De Beer, J. A. (2005). Open access scholarly communication in South Africa: current status, significance, and the role for National Information Policy in the National System of Innovation. Master thesis, Department of Information Science, Stellenbosch University, South Africa. Retrieved 
from http://eprints.rclis.org/archive/00003922/01/DeBeerJenniferMThesisFinalpdfimproved.pdf (accessed 25 October 2008).

Dewatripont, et al. (2006). Study on the economic and technical evolution of the scientific publication markets in Europe” Directorate-General for Research, European Commission. Retrieved from http://ec.europa.eu/research/sciencesociety/pdf/scientific-publication-study_en.pdf (accessed 08 December 2008).

Ezzy, D. (2002). Qualitative analysis: practice and innovation. London: Routledge.

Fang, Conghui, Zhu, and Xiaochun (2006). The open access movement in china. Interlending; Document Supply, 34(4):186-193.

Fung, I. C. H. (2008). Open access for the non-English-speaking world: overcoming the language barrier. Emerging Themes in Epidemiology, 5:1+.

Gemeda, D. (1996). Experiences of Addis Ababa University in national graduate training and research. In Erik W. Thulstrup \& Hand D. Thulstrup(Ed), Research training for development-proceedings of a conference on research training for countries with limited research capacity (p.229-244). : Roskilde: Roskilde University Press.

Gersmann, G. (2008). Open Access in the humanities. In open access: opportunities and challenges: - A handbook . The European Commission and the German Commission for UNESCO, translated from the original German edition published by the German Commission for UNESCO(p.82-83).. Retrieved from http://ec.europa.eu/research/science-society/document_library/pdf_06/openaccess-handbook_en.pdf

Glover, S. W., Webb, A. \& Gleghorn, C. (2006). Open access publishing in the biomedical sciences: could funding agencies accelerate the inevitable changes? Health Information and Libraries Journal, 23(3), 197-202.

Guedon, J. C. (2006). Open access: a symptom and a promise. In N. Jacobs (Ed.), Open access: key strategic, technical, and economic aspects (p. 27-38). Oxford: Chandos Publishing.

Hare, H. (2007). ICT in education in Ethiopia. World Bank/infoDev. Retrieved from www.infodev.org/en/Publication.402.html (accessed 12 March 2009).

Harnad, S. (2007). Challenge to "OA" publishers who oppose OA self-archiving mandates.

Licensing Digital Informatio. Retrieved

from http://www.library.yale.edu/ llicense/ListArchives/0703/msg00025.html.

Harnad, S. (2006). Opening access by overcoming Zeno's paralysis. In N. Jacobs (Ed.), Open access: key strategic, technical, and economic aspects (p.73-85).Oxford: Chandos Publishing.

ITU (2009). Measuring the information society: the ICT development index, Geneva: ITU. Retrieved from www.itu.int/ITU-

D/ict/publications/idi/2009/material/IDI2009_w5.pdf (accessed 12 March 2009).

Jacso, P. (2006). Savvy Searching: Open access to scholarly full-text documents. Online Information Review, 30(5), 587-594. 
Jones, R. , Andrew, T. and MacColl, J. (2006). The institutional repository. Chandos Publishing: Oxford.

Kitaw, Y. (2006). E-government in Africa: prospects, challenges and practices. ITU/EPFL. Retrieved from http://people.itu.int/ kitaw/egov/paper/E-Government_in_Africa.pdf (accessed 15 March 2009).

Lor, P.J. (2007). Libraries in times of open access. IOS Press, 27(4), 193-205.

Moller, A. (2006). The case for open access publishing, with special reference to open access journals and their prospects in South Africa. Master thesis, Dept of Library and Information Science, University of the Western Cape (South Africa). Retrieved from http://eprints.rclis.org/archive/00005815/01/MollerThesis.pdf (accessed 25 October 2008).

Nielsen, M. (2009). Doing science in the open. Physics World. Retrieved from http://physicsworld.com/cws/article/indepth/38904 accessed on May 12, 2009.

Nwagwu, W.E. and Ahmed, A. (2009). Building open access in Africa. Int. J. Technology Management, 45(1 / 2), 82-101. Retrieved from http://www.inderscience.com/www/pdf/ijtmv45n12_oainafrica.pdf (accessed 12 March 2009).

OECD (2007). OECD principles and guidelines for access to research data from public funding. Paris. Retrieved from http://www.oecd.org/dataoecd/9/61/38500813.pdf

Ondari-Okemwa, E. (2007). Scholarly publishing in sub-Saharan Africa in the twenty-first century: challenges and opportunities. Presented at the PKP Scholarly Publishing Conference, 11-13 July, 2007. Retrieved from http://ahero.uwc.ac.za/index.php?module=cshe\&action=downloadfile\&fileid=81 806115511849201275250.

Pappalardo, K. (2008). Understanding open access in the academic environment: A guide for authors. Open access to Knowledge (OAK) Law Project, Retrieved from http://www.oaklaw.qut.edu.au (accessed 5 October 2008).

Park, J.H and Qin, J. (2007). Exploring the willingness of scholars to accept open access: a grounded theory approach. Journal of Scholarly Publishing, 38(2), 55-84.

Pickard, A. J. (2007). Research methods in information, London: Facet Publishing.

Pickton, M. J. \& Barwick, J. (2006), “A Librarian’s guide to institutional repositories, Retrieved from https://dspace.lboro.ac.uk/dspace-jspui/handle/2134/1122 (accessed 18 March 2009).

Reason, P. (2003). Pragmatist philosophy and action research: readings and conversation with Richard Rorty. Action Research, 1 (1): 103-123.

Rockman, I. F. (2005). Distinct and expanded roles for reference librarians. Reference Services Review, 33(3), 257-258.

Sahu, D. K. \& Parmar, R. C. (2006). Open access in India. In N. Jacobs (Ed.), Open access: key strategic, technical, and economic aspects (p.175-182).Oxford: Chandos Publishing.

Salo, D. (2008). Innkeeper at the roach motel. Library Trends, 57(2). Retrieved from http://minds.wisconsin.edu/handle/1793/22088 (accessed 28 October 2008). 
Salvador Declaration on Open Access: the developing world perspective. (2005). Salvador: BIREME/PAHO/WHO. Retrieved from http://www.eifl.net/docs/Dcl-SalvadorOpenAccess-en.pdf

Solomon, D. (2008). Developing open access journals: a practical guide. Oxford: Chandos Publishing.

Srivastava, P., \& Hopwood, N. (2009). A practical iterative framework for qualitative data analysis. International Journal of Qualitative Methods , 8(1), 76-84. Retrieved from http://ejournals.library.ualberta.ca/index.php/IJQM/article/viewFile/1169/5199 (accessed on April 12, 2009).

Steele, C. (2006). Open all hours? Institutional models for open access. In N. Jacobs (Ed.), Open access: key strategic, technical, and economic aspects (p.131-138).Oxford: Chandos Publishing.

Stichweh, R. (2003). The multiple publics of science: inclusion and popularization. Retrieved from http://www.uni-bielefeld.de/soz/iw/pdf/stw_science_popular.pdf (26 March 2009).

Suber, P. (2007). What you can do to promote open access. Retrieved from http://www.earlham.edu/ peters/fos/do.htm (accessed 07 April 2009)

Suber, P. (2009). Open access policy options for funding agencies and universities. The SPARC Open Access Newsletter, issue 130 available at: http://www.earlham.edu/ peters/fos/newsletter/02-02-09.htm\#choicepoints (accessed 07 April 2009)

Suber, Peter and Nair, R. and Hussain, K. H. (2009). Open Access to public funded research: a discussion in the context of Mahatma Gandhi University digital archives of doctoral dissertations. International CALIBER 2009: E- Content Management : Challenges and Strategies, Pondicherry, India, 25-27 February 2009. [Conference Paper]. Retrieved from http://www.inflibnet.ac.in/caliber2009/CaliberPDF/8.pdf (accessed 13 May 2009).

Swan, A. (2006). Overview of scholarly communication. In N. Jacobs (Ed.), Open access: key strategic, technical, and economic aspects (p. 3-12).Oxford: Chandos Publishing.

Swan, A. (2006). The culture of open access: researchers' views and responses. In N. Jacobs (Ed.), Open access: key strategic, technical, and economic aspects (p. 65-72).Oxford: Chandos Publishing.

Swan, A. (2007). Open access and the progress of science. The American Scientist. Retrieved from wwvv.americanscientist.org on 17 October 2008.

Terry, R.\& Kiley, R. (2006). Open access to the research literature: a funder's perspective. In N. Jacobs (Ed.), Open access: key strategic, technical, and economic aspects (p. 101109). Oxford: Chandos Publishing.

Toffler, A. (1990). Power shift: knowledge, wealth, and violence at the edge of the $21^{\text {st }}$ century. New York: Bentam Books.

Ubogu, F. N. (2003). From DATAD to ETDs: the way forward.

Unpublished paper available from Certified Document Server, Humboldt University, Berlin. Retrieved from http://edoc.hu-berlin.de/conferences/etd2003/ubogufelix/PDF/index.pdf (accessed 05 April 2009)

Voges, W. (2008). Open access in the natural sciences. In Open access: opportunities and challenges: - A handbook . The European Commission and the German Commission 
for UNESCO, translated from the original German edition published by the German Commission for UNESCO (p.80-81). Retrieved from http://ec.europa.eu/research/science-society/document_library/pdf_06/openaccess-handbook_en.pdf.

Warden, B.A and Wong, S. (2007), Introduction to qualitative analysis. Retrieved from http://www.eval.org/SummerInstitute07/Handouts/si07.wongF.pdf accessed on April 12, 2009.

Willinsky, J. \& Stipek, D. (2004). Open access responds to public's hunger for knowledge. Retrieved from http://www.mercurynews.com/ci_10156512 (accessed 10 October 2008).

Willinsky, J. (2006). The access principle. Boston: MIT Press. Retrieved from http://mitpress.mit.edu/0262232421 (accessed 22 October 2008).

Yin, R. K. (2003). Case study research: design and methods. 3rd edition. London: Sage.

\section{Website References}

Berlin Declaration on Open access to Knowledge in the Sciences and Humanities (2007),

Retrieved from http://oa.mpg.de/openaccess-berlin/berlindeclaration.html .

Bethesda Statement on Open access Publishing (2003), Bethesda Statement on Open access

Publishing, released June 20, 2003, Retrieved from www.earlham.edu/,peters/fos/bethesda. htm.

Budapest Open access Initiative (2002), Retrieved from

www.soros.org/openaccess/read.shtml

Addis Ababa University http://www.aau.edu.et/

Ethiopian Ministry of Science and technology http://www.most.gov.et/

Ethiopian Development Research Institute http://www.edri.org.et/

Ethiopian Livestock Research Institute http://www.ilri.org/ 


\section{Appendix I: Concept Map of Open Access}

OA Concept Map developed by Cmaps software.

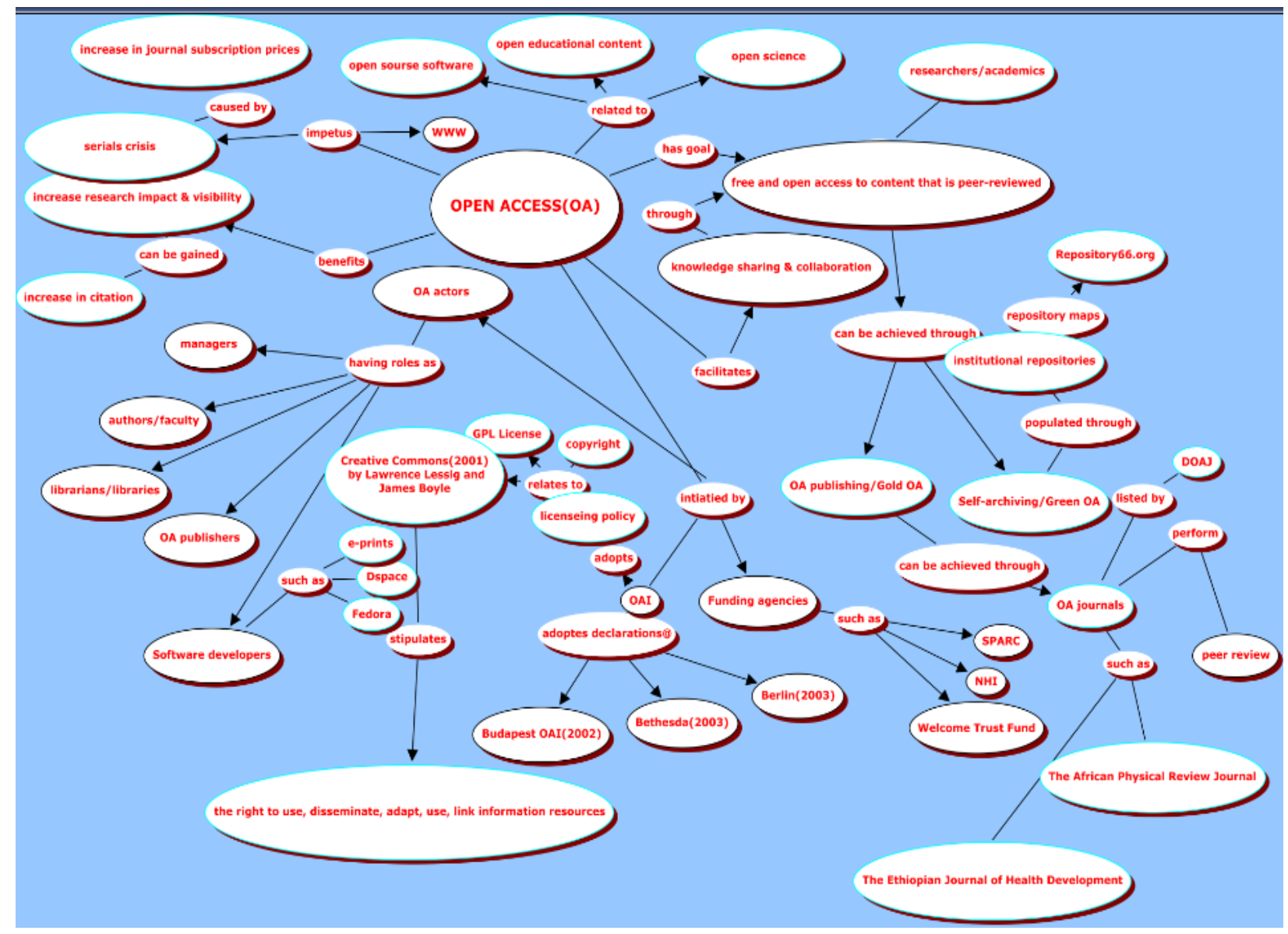




\title{
Appendix II: Semi-Structured Interview
}

\author{
The Role of Open access in Fostering Knowledge Sharing and Collaboration in Ethiopia: a case \\ study
}

\section{Interview for Researchers and Librarians}

Purpose of the interview: The study looks at how open access fosters knowledge sharing and collaboration among researchers in Ethiopia. The research seeks to investigate the status of research uptake, awareness to Open Access initiatives and models. It will look how open access models would be best suited to Ethiopian academic context hence to recommend feasible models of scholarly communication.

Your cooperation is very much appreciated. All the information will be solely used for the purpose of this research. Anonymity of the respondent and confidentiality of the information provided will be maintained.

Background Information

Your name (optional):

Faculty/Department/section Your role in your

institution:

Access to electronic resources (e-journals)

1. Where does the funding for journal subscriptions for your institution come from?

2. Do you have any problems in subscribing more journals or maintaining the existing ones?

3. What problems do you face regarding accessing research works that are published in peer reviewed journals?

4. Which projects are you participating to provide electronic journals or electronic resources to your users? (INASP/PERI, EIFL.net, TEEAL, JSTOR, HINARI, AGORA, others).

Dissemination of research results

1. How does your organization disseminate its research results?

2. What problems do you face regarding accessing research works undertaken by Ethiopian researchers?

3. How do you access research data that has been collected for other purposes but relevant for your research work?

Awareness of Open Access

4. What is your understanding of Open Access? How did you learn about it?

5. Have you ever used an Open Access journal to access research articles?

Self-archiving/Institutional repositories

6. How does your institution communicate its research reports, theses, dissertations, and other resources such as course/training materials to users of such information resources? 
7. Does your institution have an institutional repository (a central storage or database of the institution's own research results?

Mandating self-archiving

8. Does your institution have an Electronic Theses and Dissertations repository for theses and dissertations? Is submission of a copy of theses and dissertations of master and PHD students mandated by your institution?

9. Do you think there is the need for open access legislation at country/institutional/ level to mandate self-archiving for government funded research(i.e to demand researchers/authors to deposit/publish their research results openly in repositories or in any means possible for Ethiopian researchers/students and for anyone else elsewhere).

Benefits of open access for developing countries

10. What do you think are the benefits of opening access to scholarly research results (articles) to Ethiopian researchers?

Future Plans

19. What are your future plans on open access? Your plans to set up institutional repositories? Your general suggestions regarding open access

11. Any suggestions that you would like to add regarding open access to research articles?

Thank you very much for your time! 